Document downloaded from:

http://hdl.handle.net/10251/67434

This paper must be cited as:

Payri, R.; García Martínez, A.; Doménech Llopis, V.; Durrett, R.; Plazas, AH. (2012). An experimental study of gasoline effects on injection rate, momentum flux and spray characteristics using a common rail diesel injection system. Fuel. 97:390-399. doi:10.1016/j.fuel.2011.11.065.

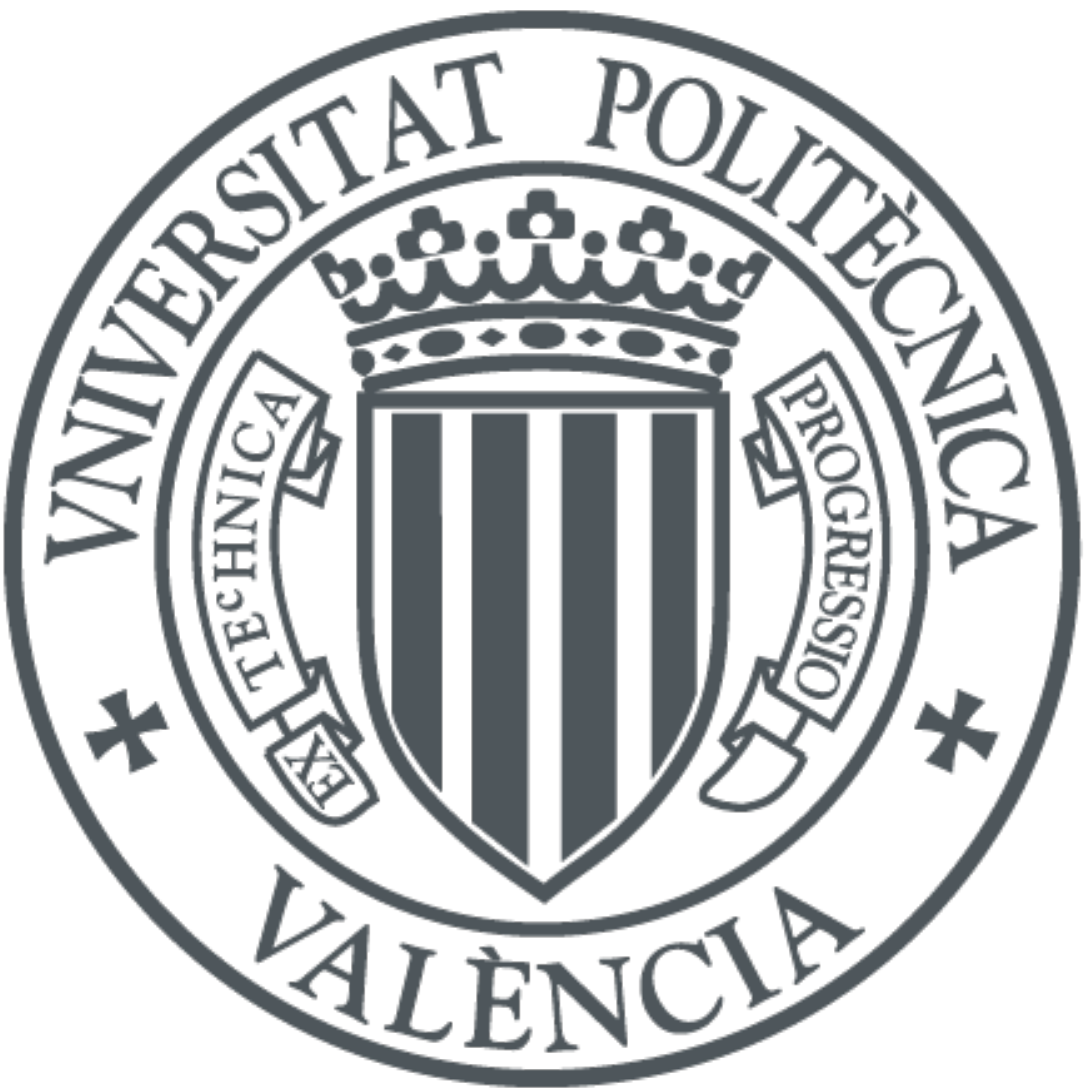

The final publication is available at

http://dx.doi.org/10.1016/j.fuel.2011.11.065

Copyright Elsevier

Additional Information 
Raul Payri, Antonio Garcia, Vicent Domenech, Russell Durrett, Alejandro H. Plazas; An experimental study of gasoline effects on injection rate, momentum flux and spray characteristics using a common rail diesel injection system; FUEL Volume: 97 Pages: 390-399 DOI: 10.1016/j.fuel.2011.11.065, 2012

\title{
An experimental study of gasoline effects on injection rate, momentum flux and spray characteristics using a common rail diesel injection system
}

\section{Raul Payri ${ }^{1}$, Antonio García ${ }^{1}$ and Vicent Domenech ${ }^{1}$ Russell. Durrett ${ }^{2}$, Alejandro H. Plazas ${ }^{2}$}

\author{
1: CMT- Motores Térmicos - Universitat Politécnica de Valencia, Camino de Vera s/n 46022 Valencia - \\ SPAIN
}

2: Diesel Engine Systems Group - Propulsion Systems Research Lab, GM R\&D Center, MC: 480-106252, 30500 Mound Rd, Warren, MI 48090-905, USA

\begin{abstract}
A comparative study using diesel fuel and gasoline has been conducted focusing on the injection process. In this paper an experimental study has been carried out comparing the effects of the different fuels on the mass flow rate, momentum flux and spray visualization in non reactive conditions with a conventional common rail system with a multi-hole injector and two different nozzle designs. Analysis of the results for both fuels show no significant variations of the momentum flux between fuels while mass flow appears to be higher for diesel with respect to gasoline when the injector needle is fully open. The use of gasoline in these injectors seems relevant in the opening and closing phases of the injector. The high-speed imaging under non-evaporative conditions revealed that both diesel and gasoline spray penetration are "quite" similar and the statistical analysis of the results shows good agreement with the literature, furthermore new parametric correlation for gasoline is presented in this work. No major differences in the spray cone angle have been found either, showing consistency with the momentum flux measurements.
\end{abstract}

Keywords: Diesel, Gasoline, injection rate, sprays momentum, spray Characteristics, spray visualization.

(*) Corresponding author: Dr. Raul Payri, rpayri@mot.upv.es 
Raul Payri, Antonio Garcia, Vicent Domenech, Russell Durrett, Alejandro H. Plazas; An experimental study of gasoline effects on injection rate, momentum flux and spray characteristics using a common rail diesel injection system; FUEL Volume: 97 Pages: 390-399 DOI: 10.1016/j.fuel.2011.11.065, 2012

\section{INTRODUCTION}

Since their introduction around century ago, internal combustion engines have played a key role, both socially and economically, in shaping the modern world. However, in recent decades, serious concerns have been raised with regard to the environmental impact of the gaseous and particulate emissions arising from operating these engines. As a result, ever tightening legislation, that restricts the levels of pollutants that may be emitted from vehicles, has been introduced by governments around the world, also the finite oil reserves and the heavy taxation of road transport makes new engine developments more important. These three factors have lead to massive pressure on vehicle manufactures to research, develop and produce ever cleaner and more fuel efficient vehicles [1],[2].

Most of the new combustion modes developed recently to reduce this problems (i.e. Homogeneous Charge Compression Ignition, Premixed Charge Compression Ignition, Controlled Autoignition, Modulated Kinetics, Smokeless Rich, etc. [3],[4],[5],[6]) are based a combination of injection rate strategies, high EGR, careful control of mixture temperatures and mixing as well as in some cases different fuels in order to simultaneously reduce soot and NOx emissions [7]. Recently the interest of the use of gasoline and others fuels in diesel injection systems to be combined with the combustion strategies has been outlined in some recent work [8],[9],[10],[11].

Nevertheless the use of gasoline in these systems is challenging and there are few studies on this topic [11]. Nowadays some research activities underline the potential of using gasoline in new combustion modes [12],[13], as a means of reducing to NOx and soot emissions in compression ignition engines.

The conventional diesel fuels used in current diesel engines have cetane numbers greater than 40 and will auto-ignite quickly after the start of injection [14]. Particularly at high loads, fuel continues to be injected after the combustion has started and this leads to high NOx and soot. If the mixing process is accelerated or if the chemical reaction is slowed down, autoignition can occur after the fuel and air are better mixed, and soot levels can be reduced. Consequently, it would be desirable to have a low 
Raul Payri, Antonio Garcia, Vicent Domenech, Russell Durrett, Alejandro H. Plazas; An experimental study of gasoline effects on injection rate, momentum flux and spray characteristics using a common rail diesel injection system; FUEL Volume: 97 Pages: 390-399 DOI: 10.1016/j.fuel.2011.11.065, 2012 temperature combustion. NOx levels can be reduced by reducing combustion temperature through a combination of lean premixed combustion, EGR or using oxygenated fuels [14]. Thus, high injection pressures and high swirl are used to increase mixing rates while high levels of cooled EGR are used to delay autoignition, this fact requires higher boost pressures to achieve the required loads. Even then, with conventional diesel fuels, low NOx and low soot with partially premixed CI combustion is possible only at low loads with reduced combustion efficiency. Hence there is a great deal of interest in developing engine combustion systems that offer the efficiency of a diesel engine, but with low smoke and low NOx. Accordingly, there is interest in studying the possibilities of a low cetane fuel as gasoline for this purpose.

A very important factor toward the goal of using cetane fuels in direct injection diesel engines is to characterize of fuel spray [15],[16],[17],[18]. Air fuel mixing is strongly influenced by the spray behavior and fuel properties, therefore the performance of a diesel engine and the requirements discussed in the previous paragraphs for new combustion modes depend on the fuel air distribution within the mixture [19],[20]. The parameters relative to spray behavior can be classified in two groups, parameters related to the injection system and parameters related to the ambient where the spray is injected. In this study, gasoline and diesel fuel have been injected using a high pressure injection system with two different nozzles to address the effects of fuel properties and to compare and better understand the influence over the injection process.

\section{OBJECTIVES AND METHODOLOGY}

The objective of this study is to investigate and to understand the behavior of injection and atomization processes using gasoline fuel in different nozzles designs, and compare with diesel fuel using a conventional diesel common rail system. To achieve this objective the followed methodology has been used: injection rate and spray momentum flux have been measured, and an injection test rig has been used in order to characterize the macroscopic characteristics of the spray under non-evaporative 
Raul Payri, Antonio Garcia, Vicent Domenech, Russell Durrett, Alejandro H. Plazas; An experimental study of gasoline effects on injection rate, momentum flux and spray characteristics using a common rail diesel injection system; FUEL Volume: 97 Pages: 390-399 DOI: 10.1016/j.fuel.2011.11.065, 2012 conditions. The combination of the injection rate and spray momentum tests allow calculation of hydraulic coefficients in each nozzle geometry. For each case, injection parameters have been conscientiously chose to match the different operating conditions of a diesel engine. The nitrogen test rig visualization has been performed afterwards to obtain and study the spray penetration and the cone angle for both fuels.

The outline of the paper is as follows. In Section 3, the facilities, tools and the fuels used are described. Section 4 describes the theoretical background of the test procedures and in Section 5 the test results are presented. In Section 6 the results are analyzed and discussed and penetration regressions for both diesel fuel and gasoline are presented. Finally, conclusions are given in Section 7.

\section{EXPERIMENTAL SETUP AND TOOLS}

The different experimental devices and facilities that are used in this work are described in this section. Firstly the two fuels used in the study and their properties are shown, then there is a short description of the injection rate meter, the spray momentum test rig, and finally the non-vaporizing spray test rig used for the macro-visualization (***the use of the specific hardware mentioned in the paper does not constitute a General Motors endorsement of those products***.)

\subsection{FUELS AND INJECTION SYSTEM}

Commercially available diesel and gasoline from a petrol station are used in this work. Differences in the fuel properties are helpful to explain the different behaviors that the fuels present when they are injected. Only fluid properties that are interesting for this study are presented. Boiling point or heating values, for example, are not relevant in nonreactive conditions. Table 1 show the main characteristics of the fuels used.

A complete conventional common rail injection system was used to generate high pressure in all the facilities and test rigs used in this work. This system includes a high pressure pump, a rail, and a piezoelectric injector as well as an electronic system to control the injection process. The injectors used 
Raul Payri, Antonio Garcia, Vicent Domenech, Russell Durrett, Alejandro H. Plazas; An experimental study of gasoline effects on injection rate, momentum flux and spray characteristics using a common rail diesel injection system; FUEL Volume: 97 Pages: 390-399 DOI: 10.1016/j.fuel.2011.11.065, 2012 in this study were BOSCH CRI 3.3 with two different nozzles designs: one with $0.097 \mathrm{~mm}$ (Nozzle 1) outlet hole diameter and another with $0.136 \mathrm{~mm}$ (Nozzle 2) outlet hole diameter. Both nozzles have 7 holes, $154^{\circ}$ aperture angle and a $1.5 \mathrm{~K}$-factor.

\subsection{INJECTION RATE METER}

Injection rate measurements were performed with a commercial injection discharge rate curve indicator (IRDCI). This device measures the chronological sequence of an individual fuel injection event. The measuring principle used is the Bosch method [21],[22] which consists of a fuel injector that inject into a fuel filled measuring tube. The back pressure is provied with a cavity filled with nitrogen, wich avoids back pressure oscillations.

The fuel discharge produces a pressure increase inside the tube, which is proportional to the increase in fuel mass. The shape of this pressure increase corresponds to the injection rate. A pressure sensor detects this pressure rise, and then an acquisition and display system processes the recorded data for further use. To obtain a good estimation of the experimental errors five repetitive measurements were carried out at the same test point (energizing time, rail pressure, and backpressure). The standard deviation for these tests is generally around $0.5 \%$ with proper calibration of the equipment.

\subsection{SPRAY MOMENTUM TEST RIG}

With this experimental test rig it is possible to determine the impingement force of one spray on a surface. This force is derivate to the spray momentum flux. The sprays are injected into the test rig that can be pressurized up to 100 bar in order to simulate discharge pressures that are representative of real pressure values inside the engine combustion chamber during the injection process. The impact force is measured with a piezo-electric pressure sensor calibrated to measure force. The sensor is located at 7 $\mathrm{mm}$ from the nozzle orifice exit in this case [23]. The frontal area of the sensor and the position are selected so that the spray impingement area is much smaller than the sensor. The pressure inside the 
Raul Payri, Antonio Garcia, Vicent Domenech, Russell Durrett, Alejandro H. Plazas; An experimental study of gasoline effects on injection rate, momentum flux and spray characteristics using a common rail diesel injection system; FUEL Volume: 97 Pages: 390-399 DOI: 10.1016/j.fuel.2011.11.065, 2012 chamber is constant and surrounds the entire spray. Under the assumption that the fuel is deflected perpendicularly to the axis direction, and due to the conservation of momentum, the force measured by the sensor is the same as the axial momentum flux at the orifice outlet or at any other axial location when the injection is in its stationary part. The stationary part of a long injection is taken to analyze the spray momentum flux [23]. Finally in table 2 the operating conditions for injection rate and spray momentum are presented.

\subsection{MACROSCOPIC SPRAY VISUALIZATION}

A non-vaporizing, nitrogen filled, spray test rig is used to obtain the penetration and the cone angle of the spray through optical diagnostic. The chamber consists of a steel cube with 3 optical access ports and various connecting flanges machined into it as shown in figure 1 . The design is modular, and ancillaries can be added depending on the required experiment. The assembly is designed for a maximum pressure of 70 bar and the temperature can bet set between values of $15-50{ }^{\circ} \mathrm{C}$. It is necessary to circulate the nitrogen through the rig because otherwise the injected fuel would obscure the windows and severely degrade the quality of the images. More information about the test rig is described in [24].

The technique used in this work to obtain macro characteristics of the spray has been Mie scattering. Mie scattering is a simple method for $2 \mathrm{D}$ spray imaging that assumes elastic scattering of light by spherical particles, where the particle is of a much larger diameter than the wavelength of the incident light. The physical information that can be extracted from planar Mie images are restricted to qualitative visualization of liquid fuel distribution and to identifying the geometrical liquid phase parameters such as spray cone angle and tip penetration [24].

The images are taken with a Phantom V12 high speed CMOS camera, equipped with a $100 \mathrm{~mm}$ focal length ZEISS lens and with two images resolutions, one of $680 \times 680$ pixels and other of $256 \times 256$ pixels. For the $680 \times 680$ resolution 10000 fps were used. The maximum spray penetration visualization 
Raul Payri, Antonio Garcia, Vicent Domenech, Russell Durrett, Alejandro H. Plazas; An experimental study of gasoline effects on injection rate, momentum flux and spray characteristics using a common rail diesel injection system; FUEL Volume: 97 Pages: 390-399 DOI: 10.1016/j.fuel.2011.11.065, 2012 window was $45 \mathrm{~mm}$. For the second configuration selected (256 x 256 resolution) 50000 fps are used. In this case the maximum spray visualization window was $16 \mathrm{~mm}$. For both cases the exposure time was 20 $\mu$ s and the pixel $/ \mathrm{mm}$ ratios was $7.92 / 1$. The illumination used is a continuous source of light. Illumination was provided by two $150 \mathrm{~W}$ quartz-halogen illuminators (Dolan-Jenner PL800), supplied by $8 \mathrm{~mm}$ optic fiber bundles positioned at $60 \mathrm{~mm}$ from the spray, sharply collimated and focused on the studied area, dispensing an illumination of $330 \mathrm{~W} / \mathrm{m} 2$ approximately.

All the experimental equipment has been synchronized with a purpose-built electronic system, using the injector trigger signal as a reference to start image acquisition. For this test, a very low injection frequency $(0.25 \mathrm{~Hz})$ is used. This long time interval between injections is required for the $\mathrm{N}_{2}$ flow in the rig to be able to remove the fuel droplets from the previous injection and, hence, to maintain similar conditions and a good optical access to the spray and avoid the appearance of the clouds of fuel in the background.

The injector is mounted so that all the spray axes are visualized simultaneously through the frontal window as could be seen in figure 2. The real challenge in image processing is the segmentation accuracy, making a thorough computed discrimination between spray and background. The images are digitally processed using purpose-developed software CALJET. The segmentation algorithm, based on the log-likelihood ratio test (LRT), has the advantage of using the three channels of RGB images for a proper determination of boundaries that are not well-defined, as in the case of sprays. This method proved to be almost completely insensitive to intensity fluctuations between pictures for the tested cases and provided better results than some other algorithms checked. Prior to the systematic use of the algorithm for parametric studies, the influence of the illumination quality on the results had to be evaluated in specific tests.

To determine the tip penetration and the spray angle, two straight lines are fitted to the first $60 \%$ of the spray contour closest to the nozzle, where the spray is assumed to behave like a steady spray. The spray angle is defined as the angle between these two straight lines. The tip penetration is defined as the 
Raul Payri, Antonio Garcia, Vicent Domenech, Russell Durrett, Alejandro H. Plazas; An experimental study of gasoline effects on injection rate, momentum flux and spray characteristics using a common rail diesel injection system; FUEL Volume: 97 Pages: 390-399 DOI: 10.1016/j.fuel.2011.11.065, 2012 distance from the origin point of the spray to the intersection point between the spray contour and the bisector of the spray angle. Results have demonstrated that the algorithm properly detects the estimated spray boundaries even in case of comparatively poor illumination. More Details of the image processing software are available in [25], [26]. The test matrix for the spray visualization in the nitrogen filled test rig is presented in Table 3 .

\section{THEORETICAL BACKGROUND}

Characterization of the spray mass flow rate and spray momentum is interesting, but when the results are compared, these test rigs are even more interesting. Payri et al [23] analyzed the theoretical definitions of injection rate (eq. 1) and momentum (eq. 2) to see influences of nozzle geometry and fluid properties on spray characteristics.

$$
\begin{aligned}
& \dot{m}=\int_{A 0} u \rho_{f} d A_{e f f} \\
& \dot{M}_{f}=\int_{A_{0}} u^{2} \cdot \rho_{f} \cdot d A_{e f f}
\end{aligned}
$$

Equation 1 and 2 are the equations for the mass flow rate and the spray momentum flux, respectively. The spray velocity at the orifice exit is $u$, and $\rho_{\mathrm{f}}$ the fuel density. The theoretical velocity of Bernoulli is $\mathrm{U}_{\mathrm{B}}$ equation (3) which only depends on the pressure drop $(\Delta \mathrm{P})$ and fuel density.

$$
u_{B}=\sqrt{\frac{2 \cdot \Delta P}{\rho_{f}}}
$$

The theoretical velocity of Bernoulli allows one to obtain a theoretical mass flow rate. A dimensionless parameter is obtained, the discharge coefficient that shows the efficiency of the nozzle fuel release. The discharge coefficient, $\mathrm{C}_{\mathrm{d}}$, is the actual mass flow divided by the theoretical mass flow. If $\mathrm{A}_{\text {geo }}$ is the geometric area of the orifice: 
Raul Payri, Antonio Garcia, Vicent Domenech, Russell Durrett, Alejandro H. Plazas; An experimental study of gasoline effects on injection rate, momentum flux and spray characteristics using a common rail diesel injection system; FUEL Volume: 97 Pages: 390-399 DOI: 10.1016/j.fuel.2011.11.065, 2012

$$
C_{d}=\frac{\dot{m}_{f}}{A_{g e o} \cdot \rho_{f} \cdot u_{B}}=\frac{\dot{m}_{f}}{A_{g e o} \sqrt{\rho_{f} \cdot 2 \cdot \Delta P}}
$$

This parameter includes two losses that could be divided in two coefficients as shown in equation 5 one is due to velocity and the other one due to area contraction. This leads to decompose the discharge coefficient as a coefficient of velocity $\mathrm{Cv}$ (eq. 6) and a coefficient of area $\mathrm{Ca}$ (eq. 7). These two dimensionless parameters are defined by the effective value divided by the theoretical (or geometric) one with $\mathrm{u}_{\mathrm{eff}}$ being the effective velocity, $\mathrm{u}_{\mathrm{B}}$ being Bernoulli theoretical velocity, $\mathrm{A}_{\mathrm{eff}}$ being the effective area, and $\mathrm{A}_{\text {geo }}$ being the geometrical area.

$$
\begin{gathered}
C_{d}=C_{v} \cdot C_{a} \\
C_{V}=\frac{u_{e f f}}{u_{B}} \\
C_{a}=\frac{A_{e f f}}{A_{g e o}}
\end{gathered}
$$

This analysis leads to the calculation of the effective velocity of the jet at the orifice exit (eq. 8), as well as the effective area of this orifice (eq. 9)

$$
\begin{aligned}
& u_{e f f}=\frac{\dot{M}_{f}}{\dot{m}_{f}}=C_{V} \cdot u_{B} \\
& A_{e f f}=\frac{\dot{m}_{f}^{2}}{\rho_{f} \cdot \dot{M}_{f}}=C_{a} \cdot A_{g e o}
\end{aligned}
$$

The spray momentum, divided by the mass flow rate gives the effective velocity $\left(\mathrm{u}_{\mathrm{eff}}\right)$ that can be also expressed as the product of the theoretical velocity from Bernoulli, $\left(\mathrm{u}_{\mathrm{B}}\right)$ and the velocity coefficient $\left(\mathrm{C}_{\mathrm{v}}\right)$. Effective area $\left(\mathrm{A}_{\mathrm{eff}}\right)$ is the other parameter, this area is obtained by dividing the square of the mass flow rate $\left(\dot{\mathrm{m}}_{\mathrm{f}}\right)$ by the fuel density $\left(\rho_{\mathrm{f}}\right)$ and the spray force $\left(\dot{\mathrm{M}}_{\mathrm{f}}\right)$. Finally, joining all the theoretical 
Raul Payri, Antonio Garcia, Vicent Domenech, Russell Durrett, Alejandro H. Plazas; An experimental study of gasoline effects on injection rate, momentum flux and spray characteristics using a common rail diesel injection system; FUEL Volume: 97 Pages: 390-399 DOI: 10.1016/j.fuel.2011.11.065, 2012 expressions, the following equations are obtained. They give the mass flow rate (eq. 10) and the spray momentum flux (eq. 11) [27] in terms of dimensionless coefficients, fuel density and pressure difference:

$$
\begin{aligned}
& \dot{m}_{f}=C_{v} \cdot C_{a} \cdot A_{g e o} \cdot \sqrt{2 \rho_{f}} \cdot \sqrt{\Delta P} \\
& \dot{M}_{f}=C_{v}^{2} \cdot C_{a} \cdot A_{g e o} \cdot 2 \cdot \Delta P
\end{aligned}
$$

\section{EXPERIMENTAL RESULTS}

In the following sections are contained all the results concerning the facilities mentioned above. In table 2 and table 3 the test parameters are presented for all the tests that have been carried out. For the mass flow rate and the spray momentum flux study, 6 different injection pressures have been used and 3 different back pressures. Also different injection times were tested as shown table \#2. Table 3 shows the test matrix for the for spray visualization. In this study $2000 \mu$ s energizing time was used and two different back pressures and four injection pressures were tested.

\subsection{INJECTION RATE MEASUREMENTS}

To compare the fuels and to better understand this part of the study, a distinction has to be made between the stationary and transient part of the injection rate shape. The mass flow rate for two fuels can be seen in figure 3. On this graph, results corresponding to three different energizing times are presented: 500, 1000, and $2000 \mu$ s. The time scale shows the time after start of energizing (ASOE) because it allows a measure of the hydraulic delay of each fluid.

At stationary conditions in the two nozzles diesel fuel has a higher injection rate than gasoline. The difference appears at the top of the curves, in the stabilized zone when the needle is fully open. It happens because the density of diesel fuel is higher than gasoline (Table 1). This effect is more noticeable in nozzle two because of the larger area of the nozzle hole. As seen in figure 3, injecton 
Raul Payri, Antonio Garcia, Vicent Domenech, Russell Durrett, Alejandro H. Plazas; An experimental study of gasoline effects on injection rate, momentum flux and spray characteristics using a common rail diesel injection system; FUEL Volume: 97 Pages: 390-399 DOI: 10.1016/j.fuel.2011.11.065, 2012 duration is shorter for injector 2 with respect to injector 1 for the same energizing time. This is due to differences in injector internal characteristics and internal valve control.

To observe the effects of different fuels, both in the transitional zone and in the stabilized zone test were run with different injections durations. In these test, it was observed the influence of gasoline properties on the injector's needle dynamic. As can be seen at the end of the injection rates, the closing is faster with gasoline. This is due to the lower value of viscosity in gasoline. When the energizing process finishes the needle descends to its initial position, in this process the viscous forces oppose the closing of the injector. Since the viscosity of diesel fuel is higher than gasoline more time is needed to close the injector due to the viscous forces slowing down the needle movement.

\subsection{MOMENTUM FLUX MEASUREMENTS}

Very similar results for momentum flux are obtained from the two fuels. It is known that the spray momentum, at the outlet, is only slightly affected by the fluid properties, the theoretical analysis developed by Payri et al. [23] shows that it is only affected by geometrical parameters and operating conditions.

As it can be seen in figure 4, the spray momentum measurements are very close for the two fuels tested and this is in accord with the expectations. For each injection pressure, no particular influence has been seen due to changing the back pressure. The spray momentum is always proportional to the pressure drop. However during the transient periods the effect of the faster needle closing for gasoline fuels due to viscous forces can be observed. Figure 4 also shows the effect of the lower viscosity of gasoline on the needle closing, particularly with nozzle 1.

\subsection{MACROVISUALIZATION OF THE SPRAYS}

The macroscopic parameters used in this study for the characterization of the spray are the penetration (S) and the spray cone angle $(\theta)$. In figure 5 a sketch of a typical spray is shown. Regarding the transient region, located at the spray tip, it has a very complicated vortical structure that makes it 
Raul Payri, Antonio Garcia, Vicent Domenech, Russell Durrett, Alejandro H. Plazas; An experimental study of gasoline effects on injection rate, momentum flux and spray characteristics using a common rail diesel injection system; FUEL Volume: 97 Pages: 390-399 DOI: 10.1016/j.fuel.2011.11.065, 2012 very difficult to study. For this reason in this study the authors have tried to avoid this region and focus on the steady part of the spray for both fuels.

As far as the internal structure of the spray penetration is concerned, this study is divided into two regions. The first region is near the nozzle orifice [27] which it is not commonly studied and one for the complete extension of the spray, in the main region or fully developed region. This has been possible because of the different optical set-up and the capabilities of the high speed camera used in the test. For each case shown in table 3 and for the same ambient conditions two tests were performed, and after processing the results were combined into one set as can be seen in figure 6, where it is possible to appreciate the large number of points measured in the initial instants using this method.

Figure 6 show the spray penetrations and angles for diesel fuel and gasoline. In these figures the mean values of penetration and cone angle data are presented, for one back pressure ( $25 \mathrm{bar}$ ) and for nozzle number 1 ( $0.097 \mathrm{~mm}$ exit diameter). It can be appreciated in this figure that the penetration is similar for both fuels and for different injection pressures.

As shown in figure 7, it is remarkable that in the study of penetration and spray angle the back pressure effect is the variable that most affects the study changing both the tightness of the jet angle of opening it, and shortening the maximum penetration.

The small hydraulic delay provides in mass flow rate is not depicted on the graphs because they are presented versus the time after start of injection (aSOI). The goal is to show the difference in penetration length and the hydraulic delay might interfere with the real spray tip penetration. Therefore, the figures are time-adjusted so that the first droplets appear at the same time for each fuel. The most important effects that figure 6 and 7 show are the very small differences in the penetration and cone angle between diesel and gasoline.

Figure 6 shows results for three different injection pressures. There do not appear to be significant differences in the first instants and in the development of the sprays for different fuels. Figure 
Raul Payri, Antonio Garcia, Vicent Domenech, Russell Durrett, Alejandro H. Plazas; An experimental study of gasoline effects on injection rate, momentum flux and spray characteristics using a common rail diesel injection system; FUEL Volume: 97 Pages: 390-399 DOI: 10.1016/j.fuel.2011.11.065, 2012 6 also shows the cone angle profiles for different fuels which have the same trend in the stabilized zone. However in the first instants of spray development the cone angle is very difficult to calculate due to the difficulties in the location of the boundary of the jet in these early moments [26][27].

The standard deviation over the results was around $1 \mathrm{~mm}$ in spray length and $2^{\circ}-2.5^{\circ}$ for the cone angle when the spray was long enough for an accurate measurement. These values come from the dispersion using a nozzle that has 7 plumes and with 5 test repetitions, in total 35 points for each time step. Therefore, the accuracy of the experimental results was very high.

\section{DISCUSSION OF THE EXPERIMENTAL RESULTS}

In this section a general discussion of the experimental results and a new regression for the penetration gasoline fuel is presented. This analysis it would be a better understanding of the fuels properties, and explain the fuel properties they affect the injection process.

\subsection{MASS FLOW AND MOMENTUM FLUX ANALYSIS}

From the preliminary theoretical development of equations (10) and (11) it would be interesting to compare the data from experimental results of the mass flow rate and spray momentum flux with these equations. Figure 8 shows the stabilized mass flow rate for both fuels and for the two different nozzles versus the square root of the difference between the injection pressure and the back pressure. These experimental results are plotted in six groups of three points which represent the different back pressures and injection pressure. As shown in figure 2, and in figure 8 , the fuel density affects the mass flow rate. The mass flow rate for diesel fuel is higher due to the higher density of diesel. This corroborates the result obtained by equation (10) and explains the differences in the mass flow rate when conditions are similar. It can be seen on this graph that when the rail pressure increases, difference in the mas flow rate between diesel fuel and gasoline becomes larger. The density has the same effect at all injection pressures, the relative difference in maximum mass flow rate has been calculated for each test 
Raul Payri, Antonio Garcia, Vicent Domenech, Russell Durrett, Alejandro H. Plazas; An experimental study of gasoline effects on injection rate, momentum flux and spray characteristics using a common rail diesel injection system; FUEL Volume: 97 Pages: 390-399 DOI: 10.1016/j.fuel.2011.11.065, 2012 and is founded to be around $6-7 \%$ between diesel and gasoline which is the same value of the square root of the densities.

In the transitional zones (opening and closing) it seems that the dynamics of the injector needle is strongly affected by fluid viscosity. The hydraulic delay is slightly longer for both the needle opening and closing when the kinematic viscosity increases (diesel fuel). Besides, the hydraulic delays are also attributed to the working of the injector holder. The fluid has to pass through small calibrated orifices in order to move the needle. This process might be affected by fluid characteristics as the flow of the liquid through the hole is influenced by viscosity. It is remarkable that the great differences in viscosity between both fuels do not imply any change in atomization regime being in the complete atomization regime in both cases.

Figure 9 show the results of spray momentum measurements for the steady state condition. Once again, only the stabilized part of the experimental result has been taken. There are no significant differences in spray momentum with the fluids tested, even when changing the injection pressure. This fact corroborates the result obtained by equation (11).

\subsubsection{SPRAY VELOCITY AND FLOW COEFFICIENTS}

As explained before in the theoretical background, the spray momentum combined with the mass flow rate give other parameters of the injection process. Thus, the effective velocity of the spray is obtained by dividing the experimental spray momentum flux by the mass flow rate. Figure 10 shows the results of this parameter. It can be directly noticed that the diesel fuel has a lower effective velocity than gasoline fuel. Different authors [23],[27] studied the diesel spray in its first millimeters and found that the influence of chamber density on penetration is very weak in the region close to the nozzle. In addition, in the area close to the nozzle, the liquid concentration is very high and this leads to the assumption that the velocity calculated, which would be the penetration velocity, could be the speed of the droplets in the spray. Another study [24] shows that the spray velocity can be theoretically calculated 
Raul Payri, Antonio Garcia, Vicent Domenech, Russell Durrett, Alejandro H. Plazas; An experimental study of gasoline effects on injection rate, momentum flux and spray characteristics using a common rail diesel injection system; FUEL Volume: 97 Pages: 390-399 DOI: 10.1016/j.fuel.2011.11.065, 2012 by the Bernoulli's equations. In this simple relationship, only two parameters are involved: the pressure drop and the fluid density. This explains that the difference seen on figure 10 is due to the density of the fuel. An increase in fuel density implies a decrease in effective velocity and an increase in pressure drop clearly increases the effective velocity.

After looking at eq (10) and equation (11) it is observed that the Cv effect is different for the two equations and that fuel density only affects the mass flow rate. With the effective velocity divided by the theoretical Bernoulli velocity it is possible to obtain $\mathrm{Cv}$. Then with equation (9) the area coefficient value could be obtained. With both values a new implicit coefficient can be obtined, the momentum coefficient [23]

$$
C_{m}=C_{v}^{2} \cdot C_{a}
$$

Figure 11 and 12 show both discharge and momentum coefficient versus Reynolds number. As observed in both cases the different value of viscosity between diesel and gasoline implies lower Reynolds number values for diesel and higher ones for gasoline. As a result, stratification in the profile is obtained. However the values of coefficients $\mathrm{C}_{\mathrm{d}}$ and $\mathrm{C}_{\mathrm{m}}$ are very similar for both fuels, only slight differences appear for the first values of diesel Since the coefficients are very similar for both fuels, the effect of the coefficients in Eq. (10) and (11) are negligible. Thus, the parameter that has the largest effect on the mass flow rate is the density as described earlier.

Since the coefficients are very similar for both fuels, the effect of the coefficients in Eq. (10) and (11) are negligible. Thus, the parameter that has the largest effect on the mass flow rate is the density as described earlier.

\subsection{SPRAY MACROSCOPIC VISUALIZATION ANALYSIS}

In this section a theoretical study of the spray cone angle penetration and angle results is presented using empirical and semi-empirical equations proposed for estimating the penetration for both 
Raul Payri, Antonio Garcia, Vicent Domenech, Russell Durrett, Alejandro H. Plazas; An experimental study of gasoline effects on injection rate, momentum flux and spray characteristics using a common rail diesel injection system; FUEL Volume: 97 Pages: 390-399 DOI: 10.1016/j.fuel.2011.11.065, 2012 diesel fuel and gasoline. The correlations are compared with others obtained previously by various authors [28], [29] .Using the experimental penetration and correlations, as did other authors [30] it will be done a discussion of the behaviors found in mixing processes for at non-evaporative conditions for diesel fuel and gasoline.

The penetration and the spray cone angle for gasoline and diesel fuel were very similar. This is consistent with the experimental results of the momentum flux. Thus the small differences observed in penetration and cone angle seems due to the spray development [19],[30]. This means that break-up, average droplets size and segregation is slightly different for the two fuels [32],[33].

The studies dedicated, at least principally, to experimental or theoretical examination of free penetration spray are very numerous for diesel fuel [28], [30],[31],[32],[33],[34] but not for gasoline working in a diesel injection system. Many studies concluded with the proposal of an empirical or semi empirical equation that estimates the instantaneous spray penetration related to diverse parameters such as density of environment, fuel density, hole geometry, etc. Hay and Jones [34] carried out a critical revision of the proposed correlations for diesel sprays and arrived at the conclusion that the best fit to the experimental results were proposals by Wakuri et al. [35] and Dent [36]. The most used are certainly those proposed by Dent and Wakuri. Later, Hiroyasu and Arai [33] proposed another correlation that includes different penetration laws depending on whether the region is before or after break-up. More recently, Naber and Siebers [28] derived a penetration correlation for non-vaporizing spray which follows the sprays penetration analyses of Wakuri et al [30] but includes significant contributions in order to estimate the arbitrary constant that normally appears in the penetration correlation. Also, Desantes et al. [38] using axi-symmetrical nozzles with different diameters, proposed a correlation where exponents affecting each parameter are consistent with previous experimental research in diesel sprays at high ambient density. 
Raul Payri, Antonio Garcia, Vicent Domenech, Russell Durrett, Alejandro H. Plazas; An experimental study of gasoline effects on injection rate, momentum flux and spray characteristics using a common rail diesel injection system; FUEL Volume: 97 Pages: 390-399 DOI: 10.1016/j.fuel.2011.11.065, 2012

In all these studies penetration $(S)$ is a function of gas density $\left(\rho_{\mathrm{g}}\right)$, diameter of the orifice outlet $\left(\mathrm{D}_{0}\right)$, the pressure drop $(\Delta \mathrm{P})$, the spray cone angle $(\theta)$ and the time $(\mathrm{t})$. Performing a fit for each fuel on all the experimental data gives the results shown in Table 4 for the prediction of spray penetration. The experimental correlation is shown in equation (13). This is the expression with Wakuri parameters with free exponents to adjust all the experimental data to obtain a new fit, The data for gasoline and diesel fuel are fitted separately.

$$
S(t)=K \Delta P^{a} \rho_{g}^{b} \tan ^{c}\left(\frac{\theta}{2}\right) t^{d} D_{0}^{e}
$$

Table 4 show the results of the nonlinear regression. Diesel and gasoline obtain similar exponents and have an R square higher than 96\%. All the coefficients have similar trends, and the same tendency for both fuels. The main differences are seen in the tangent of half angle and the small difference in the "a" coefficient value (pressure difference) and the constant $\mathrm{K}$ of adjustment. The high R-square value indicates good agreement between experimental data and equation prediction. Figure 13 shows the comparison of the experimental penetration compared with those predicted by the correlation. As can be seen from the figure the correlation is able to predict the penetration with a high degree of confidence.

In all these equations for the spray penetration, the spray momentum could also be used, and this is remarkable because as stated in section 4 the result of spray momentum flux for gasoline are almost equal to that for diesel fuel. To try to explain this behavior we can use the momentum and penetration equations. The momentum can be described as the energy of a spray delivered at the orifice exit, and if we combine equation (2) and a rectangular injection rate, then this theoretical spray momentum flux is obtained:

$$
\dot{M}_{0}=\dot{m}_{f} \cdot u_{0}=\rho_{f} \cdot \frac{\pi}{4} \cdot \varphi_{0}^{2} \cdot u_{0}^{2}
$$

In the experimental data results, with the spray momentum test rig, almost no differences have been observed. It is assumed that spray momentum remains constant along the spray travel. That is why 
Raul Payri, Antonio Garcia, Vicent Domenech, Russell Durrett, Alejandro H. Plazas; An experimental study of gasoline effects on injection rate, momentum flux and spray characteristics using a common rail diesel injection system; FUEL Volume: 97 Pages: 390-399 DOI: 10.1016/j.fuel.2011.11.065, 2012 fuel density has almost no influence in momentum flux, but when spray travels inside the chamber, both fluid and gas affect tip penetration and cone angle softly. If applied the Buckingham $\pi$ theorem [37] the theoretical spray tip penetration can be written as:

$$
S(t)=K \cdot \rho_{g}^{-1 / 4} \cdot M_{0}^{-1 / 4} \cdot t^{1 / 2} \cdot \tan ^{-\frac{1}{2}}\left(\frac{\theta}{2}\right)
$$

This once again confirms the results obtained in other sections. In equation (15) are, the gas density, the momentum flux, the spray cone angle and the time. As it has been seen the experimental time was very similar for both fuels, the regressions were dependent on the same form of the parameters in equation (15) and included the momentum flux.

Thus, the results of spray momentum flux in the study are very similar for both fuels, the small differences observed either in penetration or in cone angle come from small errors in experimental measurements and from differences in the spray development [39]. The gasoline should have a slightly shorter penetration and negligible differences in cone angle. However, with these results the authors think that mixing processes under these conditions, non-evaporative and non-reactive, are practically the same for gasoline and for diesel fuel, and this is confirmed because the momentum flux results and the spray penetration are very similar for both fuels.

\section{CONCLUSIONS}

This study presents a comparison between gasoline and diesel fuel on the injection process and spray behavior with experimental results and theoretical analysis. Experimental results were shown for the mass flow rate, the spray momentum flux and the penetration and the spray cone angle under nonevaporative conditions in a nitrogen filled test rig.

The major differences found in the comparison study are those found in injection rate. These differences are due to the density difference of the two fuels, which causes the mass flow rate for diesel to be higher than gasoline. Another interesting behavior is caused by the viscosity difference between 
Raul Payri, Antonio Garcia, Vicent Domenech, Russell Durrett, Alejandro H. Plazas; An experimental study of gasoline effects on injection rate, momentum flux and spray characteristics using a common rail diesel injection system; FUEL Volume: 97 Pages: 390-399 DOI: 10.1016/j.fuel.2011.11.065, 2012

fuels. In this study it can be appreciated how the needle opening and closing is significantly shorter in the gasoline case.

The tests shown that there are not clear differences between diesel fuel and gasoline for momentum flux and for penetration independently of the nozzle diameter. Injection rate is affected by fuel density but the spray momentum is not. This has been demonstrated by theoretical equations and the results were consistent with spray momentum correlations for gasoline and diesel fuels.

In the macrovisualization study for both nozzles and fuels, a higher dispersion for the angle measurements than for the penetration is achieved. Quite similar penetration was observed for diesel fuel and gasoline independent of the operating conditions, and as was expected in this part of study, higher injection pressure implies higher penetration and higher back pressure implies lower penetration. The statistical dependencies comparing diesel and gasoline fuels are quite similar, as well as the correlation coefficients for the spray penetration. Finally it seems with these results that in non-evaporative conditions no clear differences in the mixing process have been found.

\section{ACKNOWLEDGMENTS}

The authors wish to acknowledge General Motors for supporting this research. 
Raul Payri, Antonio Garcia, Vicent Domenech, Russell Durrett, Alejandro H. Plazas; An experimental study of gasoline effects on injection rate, momentum flux and spray characteristics using a common rail diesel injection system; FUEL Volume: 97 Pages: 390-399 DOI: 10.1016/j.fuel.2011.11.065, 2012

\section{REFERENCES}

[1] Banco, G. An Analysis of the Federal Government's Role in the Research and Development of Clean Diesels in the United States, SAE 2004-01-1753, 2004.

[2] Charlton, S.J. Developing Diesel Engines to Meet Ultra-low Emission Standards, SAE 2005-01$3628,2005$.

[3] Yu chun Hou, Xing cai Lu, Lin lin $\mathrm{Zu}$, Li bin Ji, and Zhen Huang, Effect of High-Octane Oxygenated Fuels on n-Heptane-Fueled HCCI Combustion. Energy Fuels, 20 (4), pp 1425-1433, 2006.

[4] Zhao, H., Peng, Z. and Ladommatos, N. Understanding of controlled autoignition combustion in a four strokes gasoline engine, Proc. Of Instn. Mech. Engrs, Part D., Vol. 215, pp. 1297-1310, 2001.

[5] Hardy, W. L. and Reitz, R. D. A Study of the Effects of High EGR, High Equivalence Ratio, and Mixing Time on Emissions Levels in a Heavy-Duty Diesel Engine for PCCI Combustion. Engine Research Center, University of Wisconsin - Madison. SAE paper 2006-01-0026, 2006

[6] Dong, H., Andrew, M., Ickes, S., Bohac, V. Zhen Huang, Dennis N. Assanis, Premixed lowtemperature combustion of blends of diesel and gasoline in a high speed compression ignition engine, Proceedings of the Combustion Institute, Volume 33, Issue 2, Pages 3039-3046, 2011.

[7] Rachel, L., Muncrief, C.R.W., Cruz, M. and Harold, P. Combining Biodiesel and Exhaust Gas Recirculation for Reduction in NOx and Particulate Emissions. Energy Fuels, 22 (2), pp 1285-1296, 2008.

[8] Kimura, S., Aoki, O., Ogawa, H., Muranaka, S. et al. New Combustion Concept for Ultra-Clean and High-Efficiency Small DI Diesel Engines, SAE Technical Paper 1999-01-3681, 1999.

[9] Myung Yoon, K. Je Hyung, L. and Chang Sik, L. Combustion Characteristics and NOx Emissions of a Dimethyl-Ether-Fueled Premixed Charge Compression Ignition Engine. Energy Fuels, 22 (6), pp 4206-4212, 2008.

[10] Pickett, L. and Siebers, D. Non-sooting, low flame temperature mixing-controlled DI diesel combustion SAE Paper 2004-01-1399, 2004. 
Raul Payri, Antonio Garcia, Vicent Domenech, Russell Durrett, Alejandro H. Plazas; An experimental study of gasoline effects on injection rate, momentum flux and spray characteristics using a common rail diesel injection system; FUEL Volume: 97 Pages: 390-399 DOI: 10.1016/j.fuel.2011.11.065, 2012 [11] Cheng, A.S.; Upatnieks, A.; Mueller, C. J. Investigation of fuel effects on dilute, mixingcontrolled combustion in an optical direct-injection diesel engine. Energy Fuels 2007, 21, 2002.

[12] Kalghatgi, G., Hildingsson, L. and Johansson, B. Low NOx and low smoke operation of a diesel engine using gasoline-like fuels, Proceedings of the ASME Internal Combustion Engine Division 2009 Technical Conference, ICES2009-76034, 2009.

[13] Hildingsson, L., Kalghatgi, G., Tait, N. Johansson, B. et al. Fuel Octane Effects in the Partially Premixed Combustion Regime in Compression Ignition Engines. SAE Paper 2009-01-2648, 2009.

[14] Kalghatgi, G., Risberg, P. and Ångström, H. Advantages of Fuels with High Resistance to AutoIgnition in Late-Injection, Low-Temperature, Compression Ignition Combustion, SAE Paper 2006-01$3385,2006$.

[15] Pastor, J.V., Garcia-Oliver, J.M., Nerva, J.G. and Gimenez, B. Fuel effect on the liquid phase penetration of an evaporating spray under transient diesel like conditions. Fuel doi: 10.1016 2011.05.006, 2011.

[16] Heywood J. B., Internal Combustion Engine Fundamentals. Mc Graw- Hill Series in Mechanical Engineering. MC Graw-Hill, Inc., 1988.

[17] Higgins, B. Siebers, D., Mueller, C. Aradi, A. Effects of an ignition-enhancing, diesel fuel additive on diesel spray evaporation, mixing, ignition and combustion. Symposium (international) on combustion, Volume 27, issue 2, Pages 1873-1880, 1998

[18] Browne, K., Partridge, I.M., Greeves, G. Fuel properties effects on fuel/air mixing in a experimental diesel engine. SAE Paper 860233;1986

[19] Desantes, J.M., Payri, R., Garcia, J.M., Salvador, F.J. A contribution to the understanding of isothermal diesel spray dynamics. Fuel 86 (2007) 1093-1101, 2007

[20] Pastor, J.V., López, J.J., Garcia, J M., Pastor, J M. A 1D model for description of mixing controlled inert diesel spray. Fuel 87 (2008) 2871-2885, 2008 
Raul Payri, Antonio Garcia, Vicent Domenech, Russell Durrett, Alejandro H. Plazas; An experimental study of gasoline effects on injection rate, momentum flux and spray characteristics using a common rail diesel injection system; FUEL Volume: 97 Pages: 390-399 DOI: 10.1016/j.fuel.2011.11.065, 2012

[21] Bosch, W. The fuel rate indicator: a new instrument for display of the characteristic of individual injection. SAE Paper 660749, 1966.

[22] Payri, R., Salvador, F J., Gimeno, J., Bracho, G. A, New methodology for correcting the signal cumulative phenomenon on injection rate measurements. Exp. Tech, Vol 15, 46-49, 2008

[23] Payri, R., Garcia, J.M., Salvador, F.J., Gimeno, J. Using spray momentum flux measurements to understand the influence of diesel nozzle geometry on spray characteristics. Fuel 2005, 84, 551-561.

[24] Desantes, J.M., Payri, R., Salvador, F.J., Soare, V. Determination of diesel sprays characteristics in real engine in-cylinder air density and pressure conditions. J Mech. Sci. Technol., 19, 2040-2052, 2005

[25] Pastor, J.V., Arregle, J., Palomares, A. Diesel spray image segmentation with a likelihood ratio test. Appl. Opt. 2001, 40 (No. 17), 2876-2885., 2001

[26] Macian, V.,Payri, R., Garcia, A., Bardi, M., Experimental Evaluation of the Best Approach for Diesel Spray Images Segmentation, Experimental Technique, doi:10.1111/j.1747-1567.2011.00730.x 2011

[27] Payri, R., Salvador, F.J., Gimeno, J., and De la Morena, J. Macroscopic behavior of diesel sprays in the near-nozzle field, SAE Paper 2008-01-0929, 2008.

[28] Naber, J., and Siebers, D. Effects of gas density and vaporization on penetration and dispersion of diesel sprays, SAE Paper 960034, 1996.

[29] Dent, J C. A basis for the comparison of various experimental methods for studying spray penetration, SAE Paper 710571, 1971.

[30] Wakuri, Y. Fujii, M. Amitani, T. Tsuneva, R. Studies of the penetration of a fuel spray in a diesel engine, J. Soc. Mech. Eng. 3, 123-130, 1960.

[31] Bermudez, V., Payri, R., Salvador, F.J., and Plazas, A.H., Study of the influence of nozzle seat type on injection rate and spray behavior, ImechE. Journal of automobile engineering. Part D, Vol 219, pp. $677-689,2005$ 
Raul Payri, Antonio Garcia, Vicent Domenech, Russell Durrett, Alejandro H. Plazas; An experimental study of gasoline effects on injection rate, momentum flux and spray characteristics using a common rail diesel injection system; FUEL Volume: 97 Pages: 390-399 DOI: 10.1016/j.fuel.2011.11.065, 2012

[32] Hiroyasu, H. Arai, M. Structures of fuel sprays in diesel engines, SAE Paper 900475, 1990.

[33] Hiroyasu, H. Arai, M. Shimizu, M. Break-up length of liquid jet and internal flow in a nozzle. ICLASS-91, Gaithersburg, Maryland; 1991.

[34] Hay, P. and Jones, P. L. Comparison of the various correlations for spray penetration. SAE paper $720776,1972$.

[35] Wakuri Y, Fuji M, Amitani T, Tsnumeya R. Studies of the penetration of a fuel spray in diesel engine, Bull JSME; 3(9):123-30. 1960.

[36] Dent, J. Basis for comparison of various experimental methods for studying spray penetration. SAE paper 710571, 1971.

[37] Buckingham, E. Model experiments and the forms of empirical equations. Trans. Am. Soc. Mech. Eng., 37, 263-296, 1915.

[38] Desantes, J.M., Payri, R., Salvador, F.J., Soare, V. Study of the Influence of Geometrical and Injection Parameters on Diesel Sprays Characteristics in isothermal conditions. SAE Paper 2005-010913, 2005.

[39] Desantes, J.M., Payri, R., Salvador, F.J., Gil, A. Development and validation for a theoretical model for Diesel spray penetration. Fuel 85, 910-917, 2006. 
Raul Payri, Antonio Garcia, Vicent Domenech, Russell Durrett, Alejandro H. Plazas; An experimental study of gasoline effects on injection rate, momentum flux and spray characteristics using a common rail diesel injection system; FUEL Volume: 97 Pages: 390-399 DOI: 10.1016/j.fuel.2011.11.065, 2012

\section{Appendix A equations}

Eq. (A.1)

$$
\dot{m}=\int_{A 0} u \rho_{f} d A_{e f f}
$$

Eq. (A.2)

$$
\dot{M}_{f}=\int_{A_{0}} u^{2} \cdot \rho_{f} \cdot d A_{e f f}
$$

Eq. (A.3)

$$
u_{B}=\sqrt{\frac{2 . \Delta P}{\rho_{f}}}
$$

Eq. (A.4)

$$
C_{d}=\frac{\dot{m}_{f}^{2}}{A_{g e o} \cdot \rho_{f} \cdot u_{B}}=\frac{\dot{m}_{f}^{2}}{A_{g e o} \cdot \sqrt{\rho_{f} \cdot 2 \Delta P}}
$$

Eq. (A.5)

$$
C_{d}=C_{v} \cdot C_{a}
$$

Eq. (A.6)

$$
C_{V}=\frac{u_{e f f}}{u_{B}}
$$

Eq. (A.7)

$$
C_{a}=\frac{A_{e f f}}{A_{g e o}}
$$

Eq. (A.8)

$$
u_{\text {eff }}=\frac{\dot{M}_{f}}{\dot{m}_{f}}=C_{V} \cdot u_{B}
$$

Eq. (A.9)

$$
A_{e f f}=\frac{\dot{m}_{f}^{2}}{\rho_{f} \cdot \dot{M}_{f}}=C_{a} \cdot A_{g e o}
$$

Eq. (A.10)

$$
\dot{m}_{f}=C_{v} \cdot C_{a} \cdot A_{g e o} \cdot \sqrt{2 \rho_{f}} \cdot \sqrt{\Delta P}
$$

Eq. (A.11)

$$
\dot{M}_{f}=C_{v}^{2} \cdot C_{a} \cdot A_{g e o} \cdot 2 \cdot \Delta P
$$

Eq. (A.12)

$$
C_{m}=C_{v}^{2} \cdot C_{a}
$$

Eq. (A.13)

$$
S(t)=K \cdot \Delta P^{a} \cdot \rho_{g}^{b} \cdot \tan ^{c}\left(\frac{\theta}{2}\right) \cdot t^{d} \cdot D_{0}^{e}
$$

Eq. (A.14)

$$
\dot{M}_{0}=\dot{m}_{f} \cdot u_{0}=\rho_{f} \cdot \frac{\pi}{4} \cdot \varphi_{0}^{2} \cdot u_{0}^{2}
$$

Eq. (A.15)

$$
S(t)=K \cdot \rho_{g}^{-1 / 4} \cdot M_{0}^{-1 / 4} \cdot t^{1 / 2} \cdot \tan ^{-\frac{1}{2}}\left(\frac{\theta}{2}\right)
$$


Raul Payri, Antonio Garcia, Vicent Domenech, Russell Durrett, Alejandro H. Plazas; An experimental study of gasoline effects on injection rate, momentum flux and spray characteristics using a common rail diesel injection system; FUEL Volume: 97 Pages: 390-399 DOI: 10.1016/j.fuel.2011.11.065, 2012 Appendix B Figure captions

Fig. (B.1) Figure 1: Nitrogen test rig sketch with High speed camera

Fig. (B.2) Figure 2: Diesel and gasoline injection pressure 1200 bar and Back Pressure 25 bar Nozzle1 $700 \mu$ s after SOE in 680x680 resolution and 10000 fps

Fig. (B.3) Figure 3: Mass flow rate at 1200 bar (BP=50 bar, ET 500, 1000 and $2000 \mu$ s)

Fig. (B.4) Figure 4: Spray momentum flux at 1200 bar $(B P=25,50$ and 75 bar, ET $2000 \mu$ s)

Fig. (B.5) Figure 5: Spray macroscopic characteristics

Fig. (B.6) Figure 6: Spray tip Penetration and cone angle for different injection pressure and 25 bar back pressure

Fig. (B.7) Figure 7: Spray tip Penetration and cone angle for 25 and 50 bar back pressures

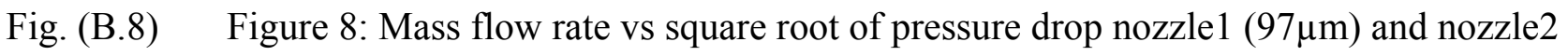
$(136 \mu \mathrm{m})$

Fig. (B.9) Figure 9: Stabilized spray momentum vs pressure drop for nozzle1 $(97 \mu \mathrm{m})$ and nozzle2 $(136 \mu \mathrm{m})$

Fig. (B.10) Figure 10: Effective velocity of the spray vs pressure drop for nozzle1 $(97 \mu \mathrm{m})$ and nozzle2 $(136 \mu \mathrm{m})$

Fig. (B.11) Figure 11: Discharge and momentum coefficients for Nozzle1

Fig. (B.12) Figure 12: Discharge and momentum coefficients for Nozzle2

Fig. (B.13) Figure 13: Predicted vs measured penetration for diesel and gasoline 
Raul Payri, Antonio Garcia, Vicent Domenech, Russell Durrett, Alejandro H. Plazas; An experimental study of gasoline effects on injection rate, momentum flux and spray characteristics using a common rail diesel injection system; FUEL Volume: 97 Pages: 390-399 DOI: 10.1016/j.fuel.2011.11.065, 2012

\section{Appendix C Table captions}

Tab. (C.1) Table 1: Characteristics of fuels used in the study

Tab. (C.2) Table 2: Test matrix for injection rate and spray momentum (* only in injection rate test)

Tab. (C.3) Table 3: Test matrix for the spray visualization

Tab. (C.4) Table 4: Experimental correlation for both fuels 
Raul Payri, Antonio Garcia, Vicent Domenech, Russell Durrett, Alejandro H. Plazas; An experimental study of gasoline effects on injection rate, momentum flux and spray characteristics using a common rail diesel injection system; FUEL Volume: 97 Pages: 390-399 DOI: 10.1016/j.fuel.2011.11.065, 2012

Table 1: Characteristics of fuels used in the study

\begin{tabular}{l|lllc}
\hline Fuel & $\begin{array}{l}\text { Density } \\
{\left[15^{\circ} \mathrm{C}\right]}\end{array}$ & $\begin{array}{l}\text { Density } \\
{\left[40^{\circ} \mathrm{C}\right]}\end{array}$ & $\begin{array}{l}\text { Viscosity } \\
{\left[40^{\circ} \mathrm{C}\right]}\end{array}$ & $\begin{array}{c}\text { Surface tension } \\
{\left[20^{\circ} \mathrm{C}\right]}\end{array}$ \\
\hline$[-]$ & {$\left[\mathrm{Kg} / \mathrm{m}^{3}\right]$} & {$\left[\mathrm{Kg} / \mathrm{m}^{3}\right]$} & {$[\mathrm{cStk}]$} & {$[\mathrm{mN} / \mathrm{m}]$} \\
Diesel & 832 & 820 & 2.38 & 28.9 \\
Gasoline & 733 & 722 & 0.55 & 21.3 \\
\hline
\end{tabular}

Table 2: Test matrix for injection rate and spray momentum (* only in injection rate test)

\begin{tabular}{c|cccc}
\hline Fuel [-] & $P_{\text {inj }}[\mathrm{bar}]$ & $P_{\text {back }}[\mathrm{bar}]$ & $E T[\mu \mathrm{s}]$ & Nozzle $[\mu \mathrm{m}]$ \\
\hline Diesel & $300 *$ & $25-50-75$ & $500 *-1000 *-2000$ & $97-136$ \\
Diesel & 600 & $25-50-75$ & $500 *-1000 *-2000$ & $97-136$ \\
Diesel & 900 & $25-50-75$ & $500 *-1000 *-2000$ & $97-136$ \\
Diesel & 1200 & $25-50-75$ & $500 *-1000 *-2000$ & $97-136$ \\
Diesel & 1500 & $25-50-75$ & $500 *-1000 *-2000$ & $97-136$ \\
Diesel & $1800 *$ & $25-50-75$ & $500 *-1000 *-2000$ & $97-136$ \\
Gasoline & $300 *$ & $25-50-75$ & $500 *-1000 *-2000$ & $97-136$ \\
Gasoline & 600 & $25-50-75$ & $500 *-1000 *-2000$ & $97-136$ \\
Gasoline & 900 & $25-50-75$ & $500 *-1000 *-2000$ & $97-136$ \\
Gasoline & 1200 & $25-50-75$ & $500 *-1000 *-2000$ & $97-136$ \\
Gasoline & 1500 & $25-50-75$ & $500 *-1000 *-2000$ & $97-136$ \\
Gasoline & $1800 *$ & $25-50-75$ & $500 *-1000 *-2000$ & $97-136$ \\
\hline
\end{tabular}


Raul Payri, Antonio Garcia, Vicent Domenech, Russell Durrett, Alejandro H. Plazas; An experimental study of gasoline effects on injection rate, momentum flux and spray characteristics using a common rail diesel injection system; FUEL Volume: 97 Pages: 390-399 DOI: 10.1016/j.fuel.2011.11.065, 2012

Table 3: Test matrix for the spray visualization

\begin{tabular}{c|ccccc}
\hline Test & Fuel & $P_{\text {inj }}$ & $P_{\text {back }}$ & ET & Nozzle \\
& {$[-]$} & {$[$ bar $]$} & {$[$ bar $]$} & {$[\mu \mathrm{s}]$} & {$[-]$} \\
\hline 1 & Diesel & 600 & $25-50$ & 2000 & $1-2$ \\
2 & Diesel & 900 & $25-50$ & 2000 & $1-2$ \\
3 & Diesel & 1200 & $25-50$ & 2000 & $1-2$ \\
4 & Diesel & 1500 & $25-50$ & 2000 & $1-2$ \\
5 & Gasoline & 600 & $25-50$ & 2000 & $1-2$ \\
6 & Gasoline & 900 & $25-50$ & 2000 & $1-2$ \\
7 & Gasoline & 1200 & $25-50$ & 2000 & $1-2$ \\
8 & Gasoline & 1500 & $25-50$ & 2000 & $1-2$ \\
\hline
\end{tabular}

Table 4: Experimental correlation for both fuels

\begin{tabular}{l|ll}
\hline & Diesel & Gasoline \\
\hline & Experimental & Experimental \\
& correlation & correlation \\
k & 0.167 & 0.142 \\
$\mathrm{a}$ & 0.218 & 0.244 \\
$\mathrm{~b}$ & -0.287 & -0.273 \\
$\mathrm{c}$ & 0.022 & 0.045 \\
$\mathrm{~d}$ & 0.609 & 0.61 \\
$\mathrm{e}$ & 0.231 & 0.245 \\
$\mathrm{R}^{2}$ & 96.57 & 97.27 \\
\hline
\end{tabular}


Raul Payri, Antonio Garcia, Vicent Domenech, Russell Durrett, Alejandro H. Plazas; An experimental study of gasoline effects on injection rate, momentum flux and spray characteristics using a common rail diesel injection system; FUEL Volume: 97 Pages: 390-399 DOI: 10.1016/j.fuel.2011.11.065, 2012 HS CAMERA
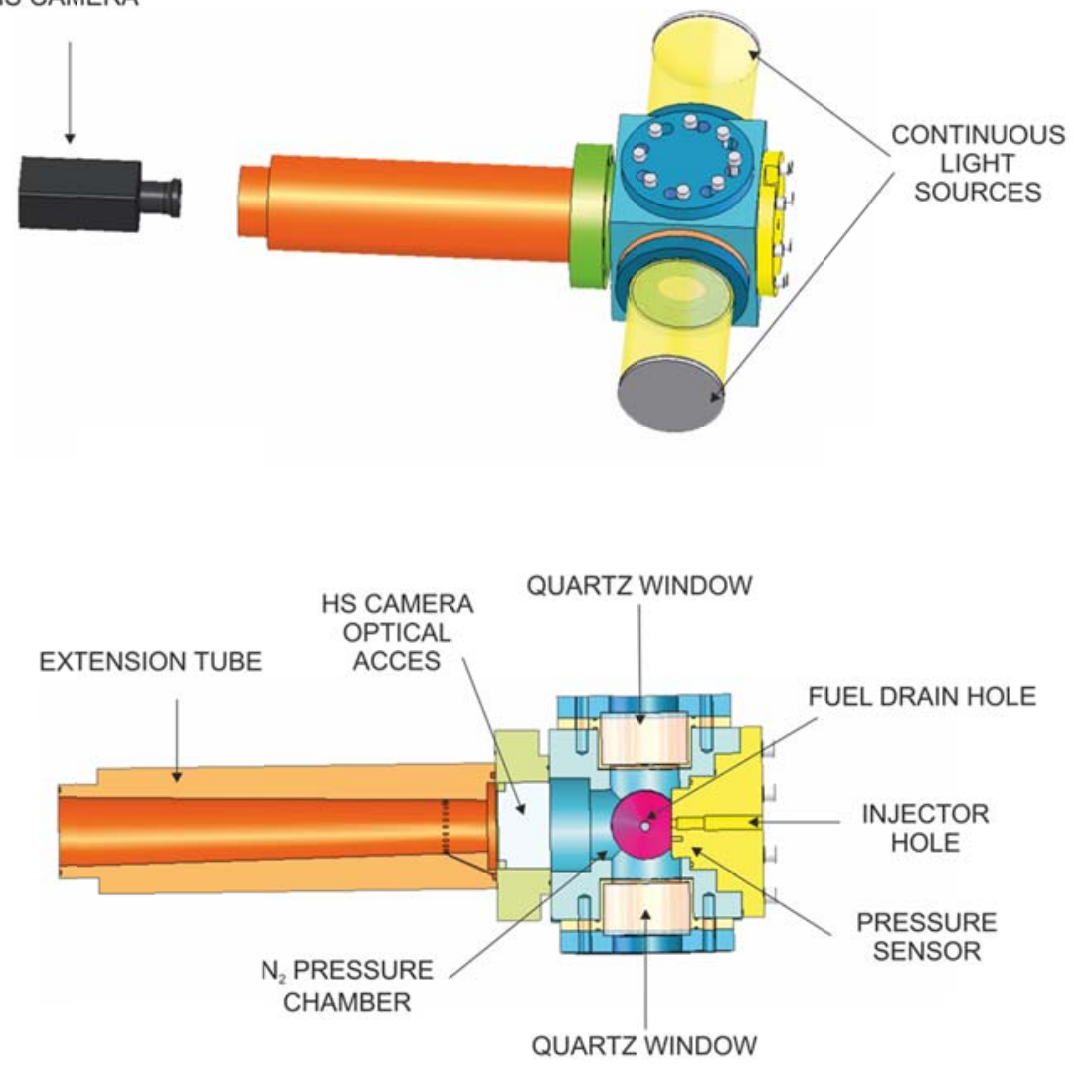

Fig 1
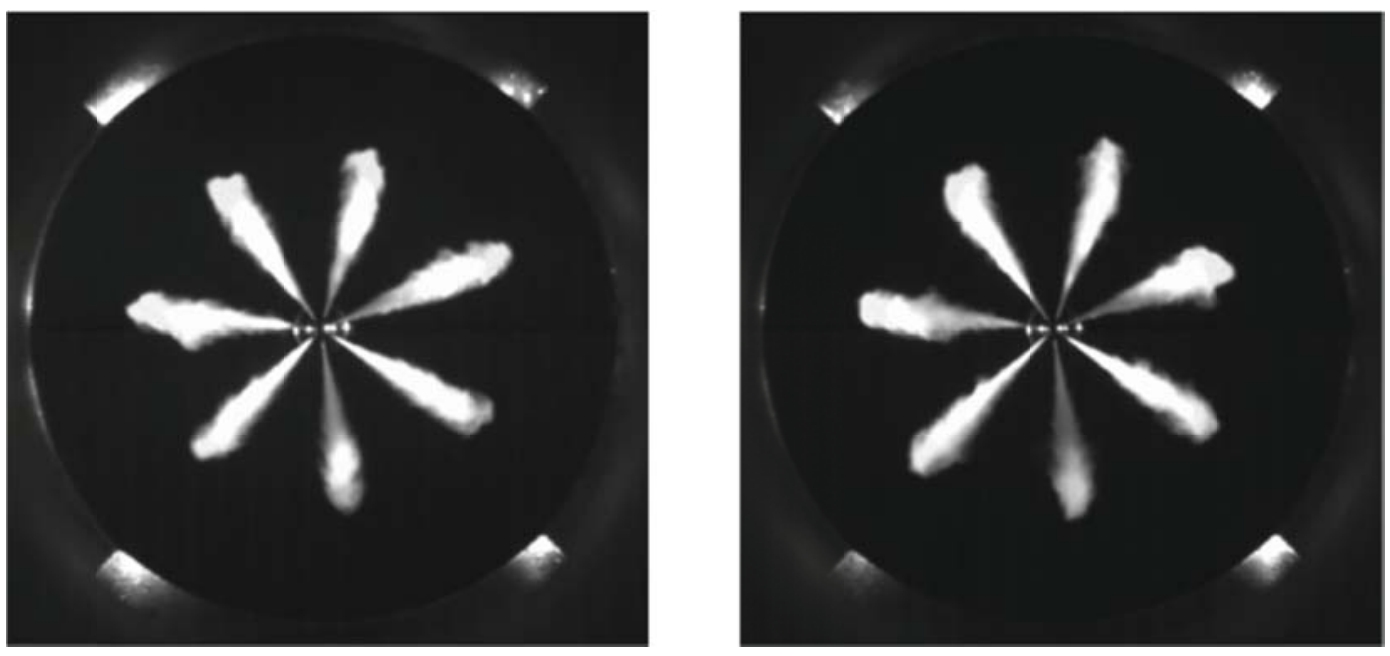

Fig 2 
Raul Payri, Antonio Garcia, Vicent Domenech, Russell Durrett, Alejandro H. Plazas; An experimental study of gasoline effects on injection rate, momentum flux and spray characteristics using a common rail diesel injection system; FUEL Volume: 97 Pages: 390-399 DOI: 10.1016/j.fuel.2011.11.065, 2012
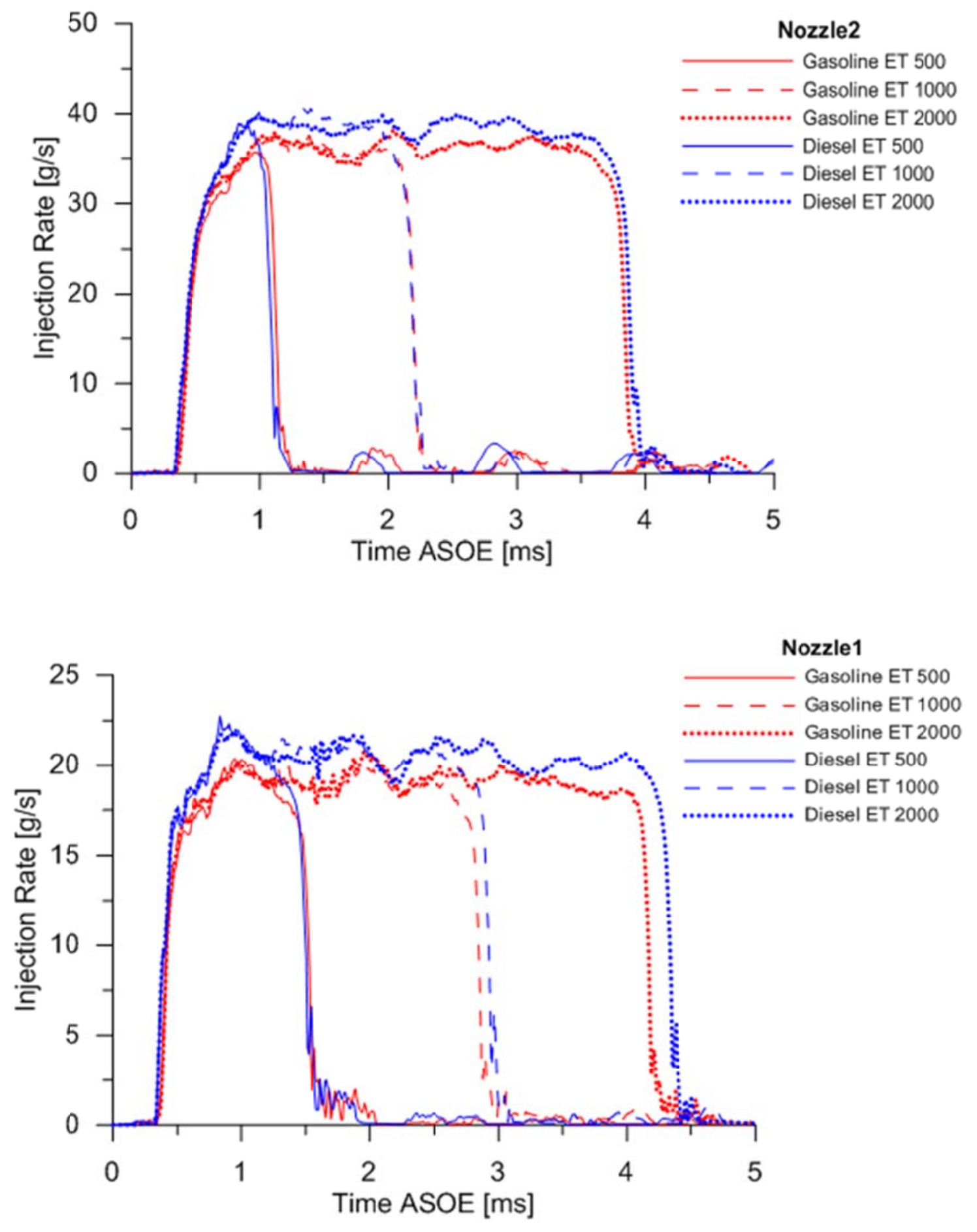

Fig 3 
Raul Payri, Antonio Garcia, Vicent Domenech, Russell Durrett, Alejandro H. Plazas; An experimental study of gasoline effects on injection rate, momentum flux and spray characteristics using a common rail diesel injection system; FUEL Volume: 97 Pages: 390-399 DOI: 10.1016/j.fuel.2011.11.065, 2012
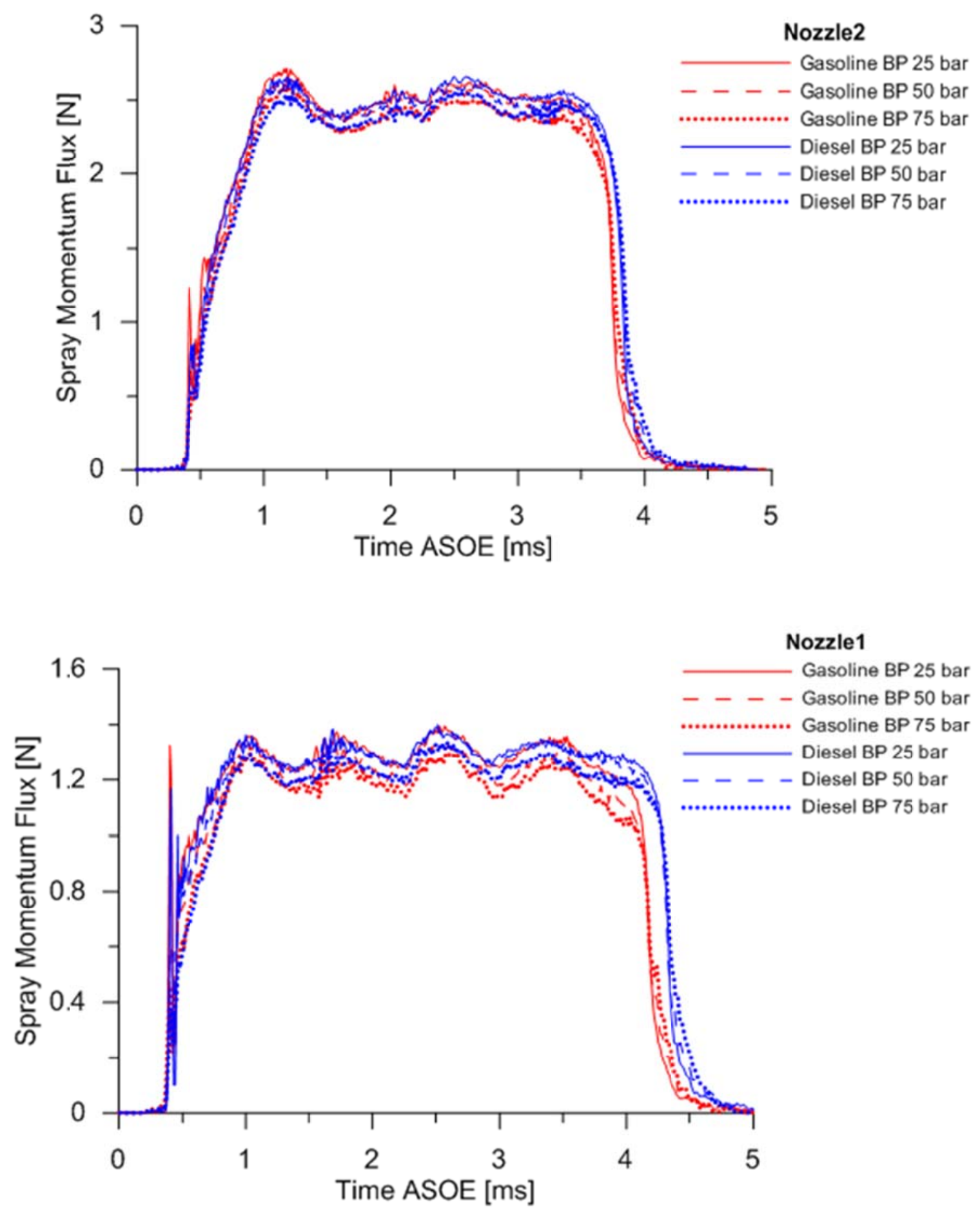

Fig 4 
Raul Payri, Antonio Garcia, Vicent Domenech, Russell Durrett, Alejandro H. Plazas; An experimental study of gasoline effects on injection rate, momentum flux and spray characteristics using a common rail diesel injection system; FUEL Volume: 97 Pages: 390-399 DOI: 10.1016/j.fuel.2011.11.065, 2012

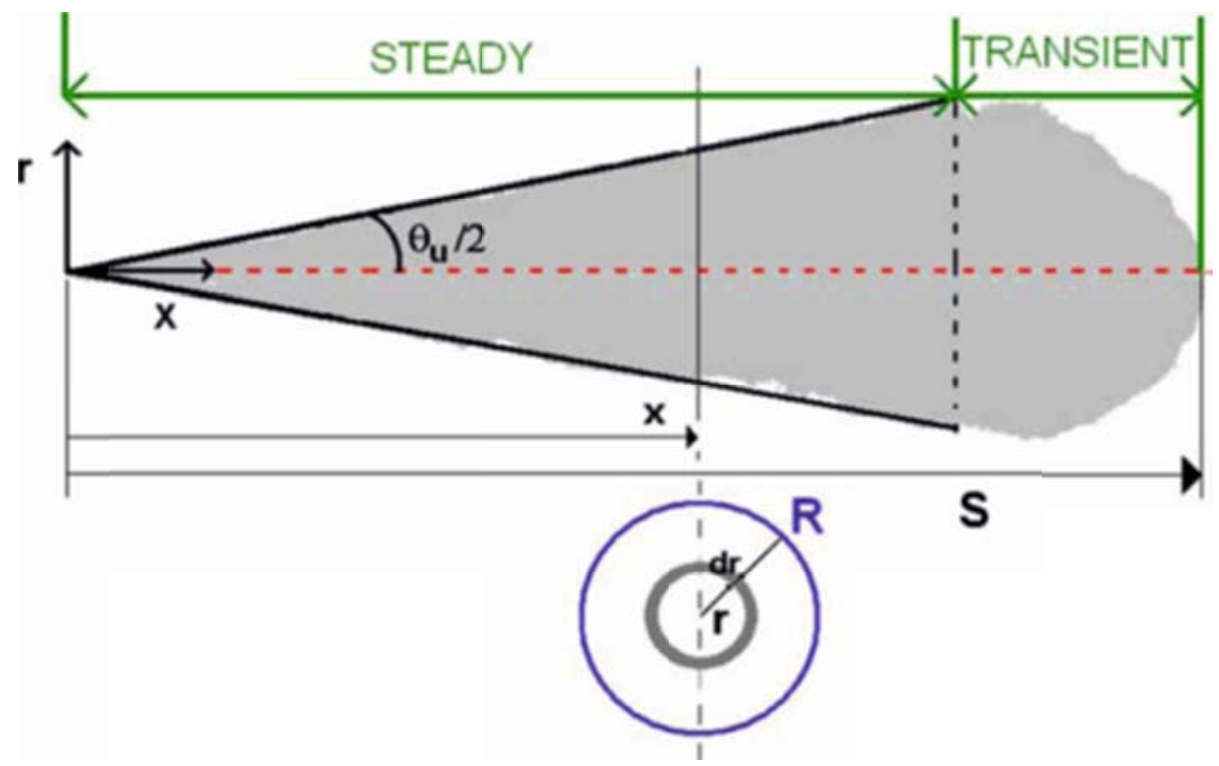

Fig 5
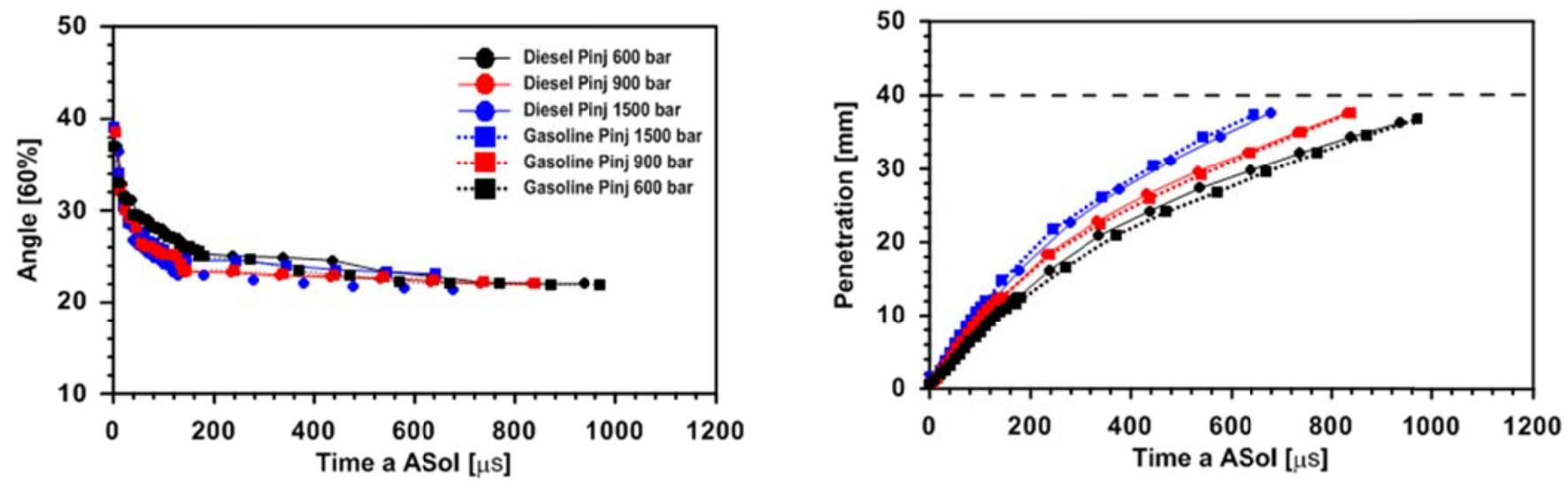

Fig 6 
Raul Payri, Antonio Garcia, Vicent Domenech, Russell Durrett, Alejandro H. Plazas; An experimental study of gasoline effects on injection rate, momentum flux and spray characteristics using a common rail diesel injection system; FUEL Volume: 97 Pages: 390-399 DOI: 10.1016/j.fuel.2011.11.065, 2012
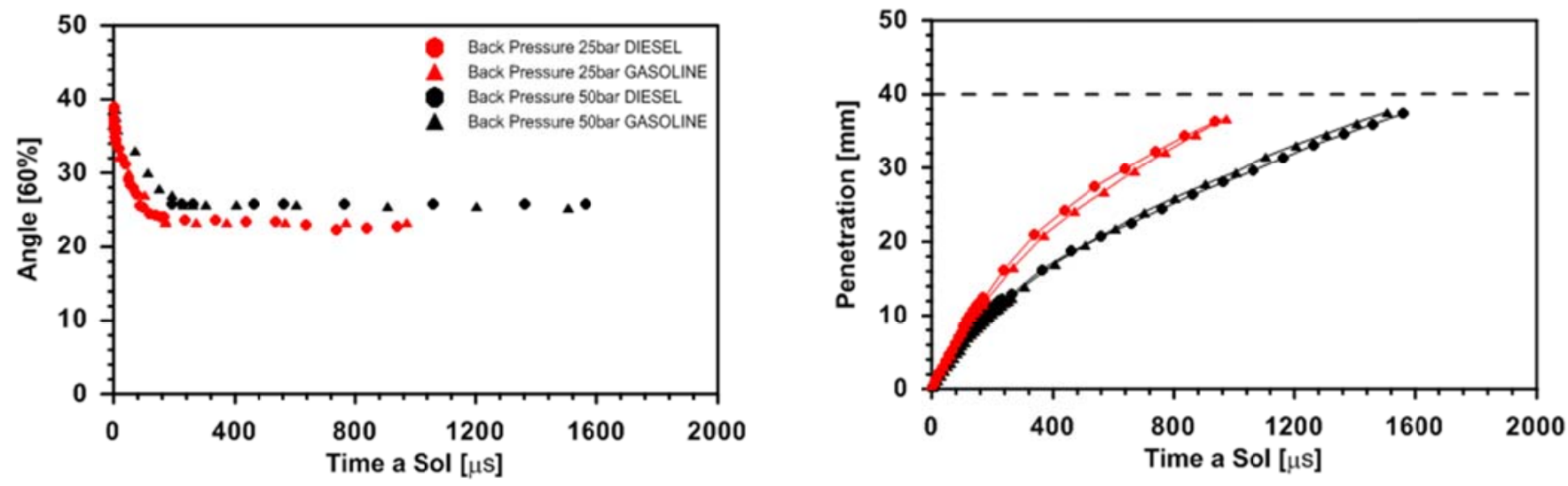

Fig 7
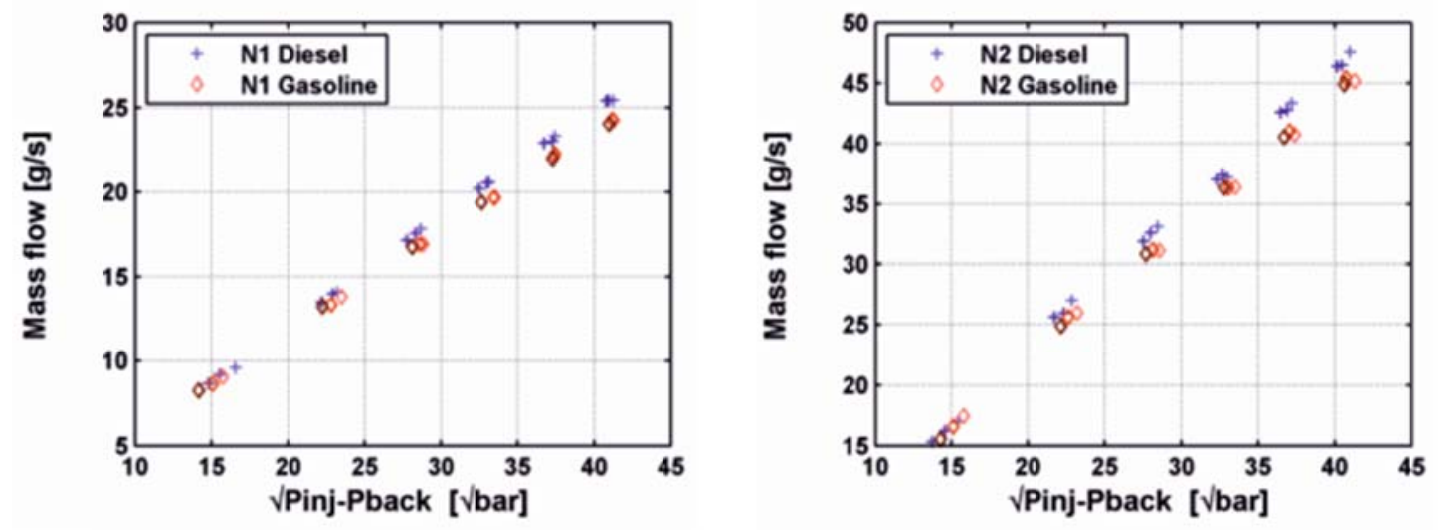

Fig 8 
Raul Payri, Antonio Garcia, Vicent Domenech, Russell Durrett, Alejandro H. Plazas; An experimental study of gasoline effects on injection rate, momentum flux and spray characteristics using a common rail diesel injection system; FUEL Volume: 97 Pages: 390-399 DOI: 10.1016/j.fuel.2011.11.065, 2012
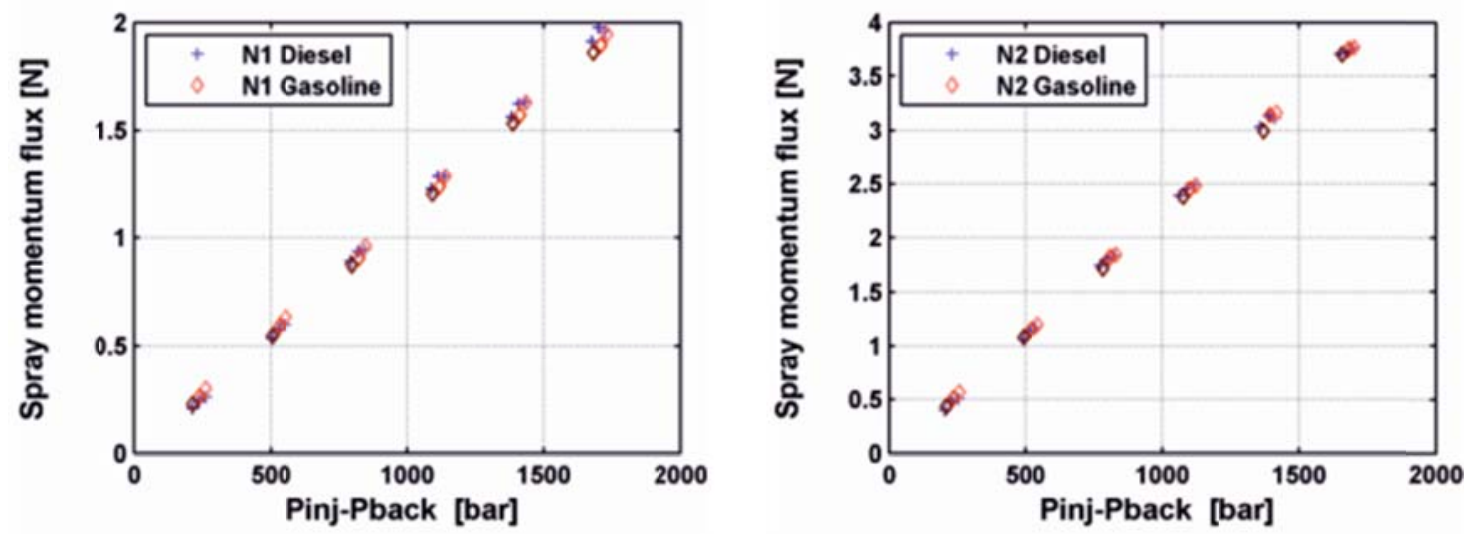

Fig 9
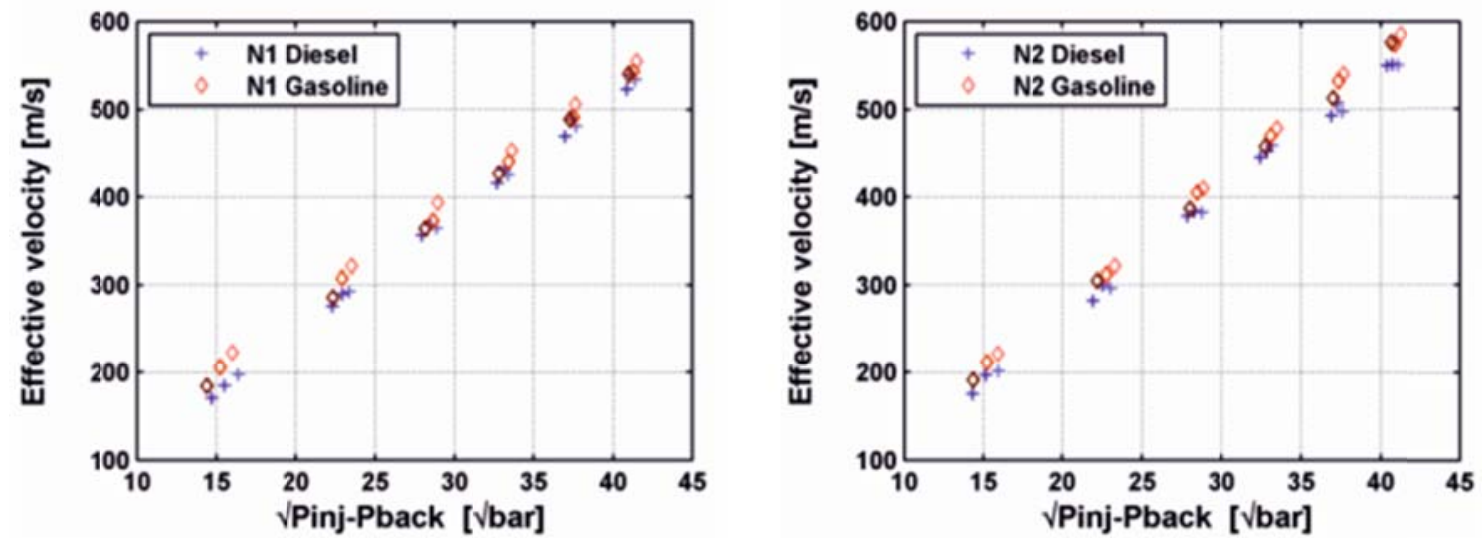

Fig 10 
Raul Payri, Antonio Garcia, Vicent Domenech, Russell Durrett, Alejandro H. Plazas; An experimental study of gasoline effects on injection rate, momentum flux and spray characteristics using a common rail diesel injection system; FUEL Volume: 97 Pages: 390-399 DOI: 10.1016/j.fuel.2011.11.065, 2012
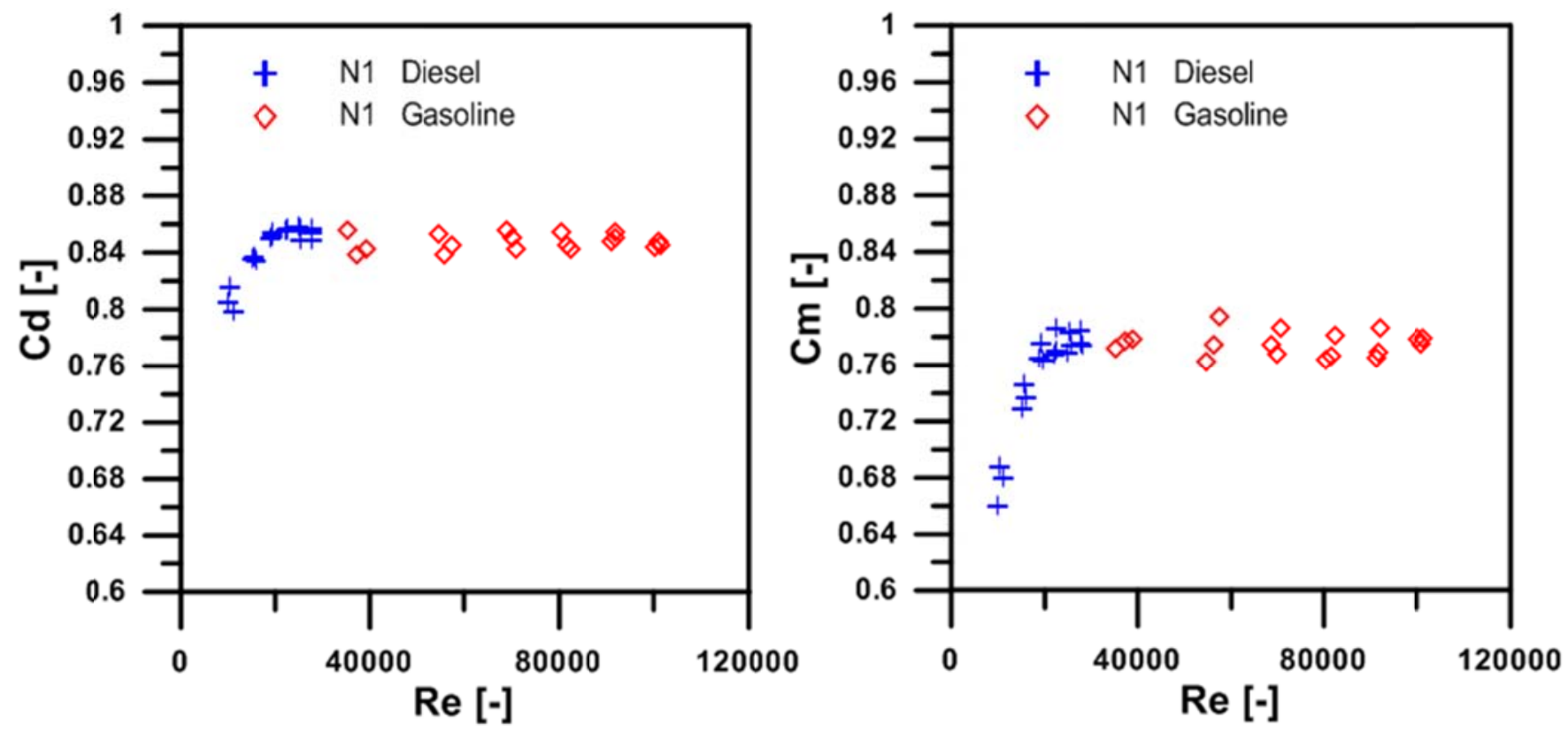

Fig 11
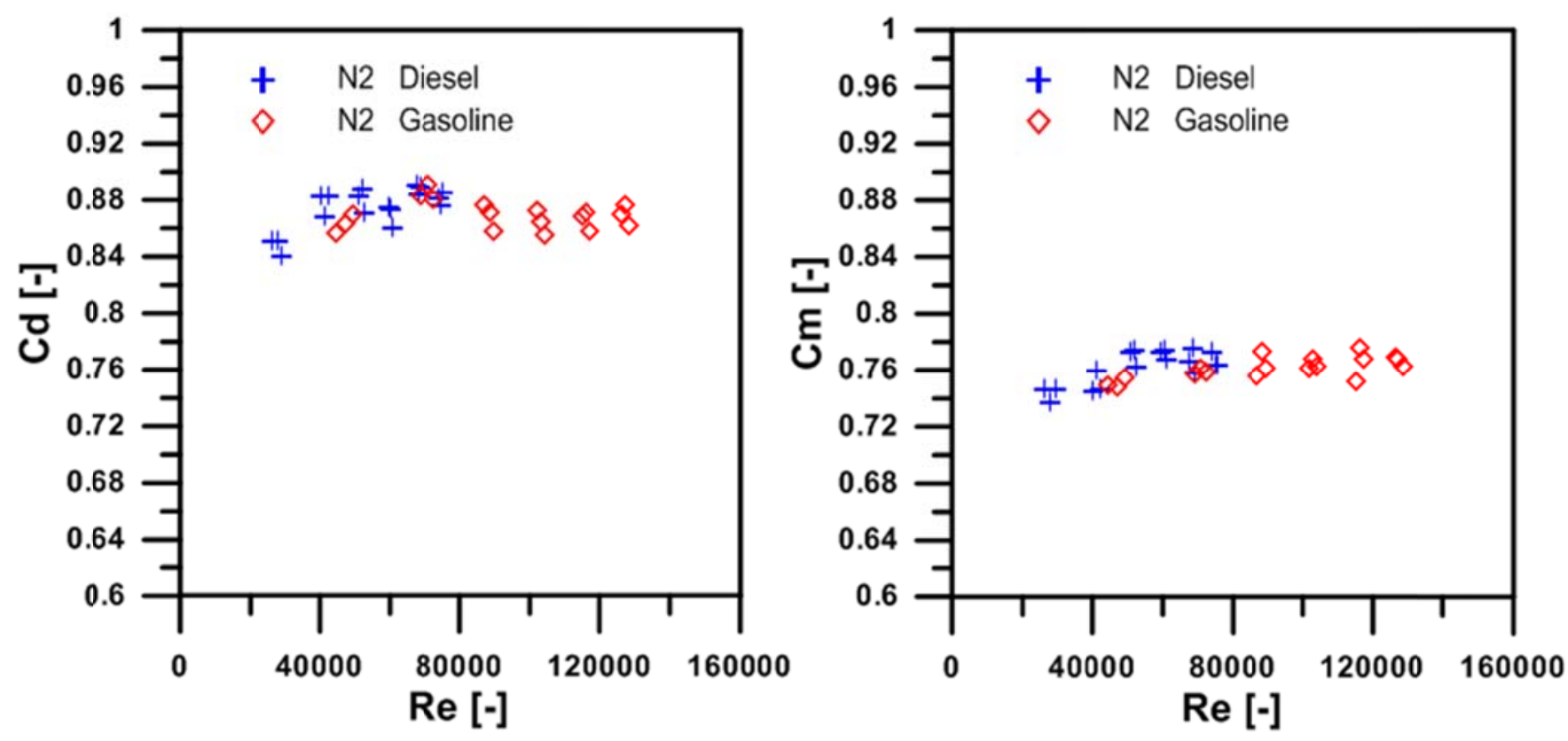

Fig 12 
Raul Payri, Antonio Garcia, Vicent Domenech, Russell Durrett, Alejandro H. Plazas; An experimental study of gasoline effects on injection rate, momentum flux and spray characteristics using a common rail diesel injection system; FUEL Volume: 97 Pages: 390-399 DOI: 10.1016/j.fuel.2011.11.065, 2012
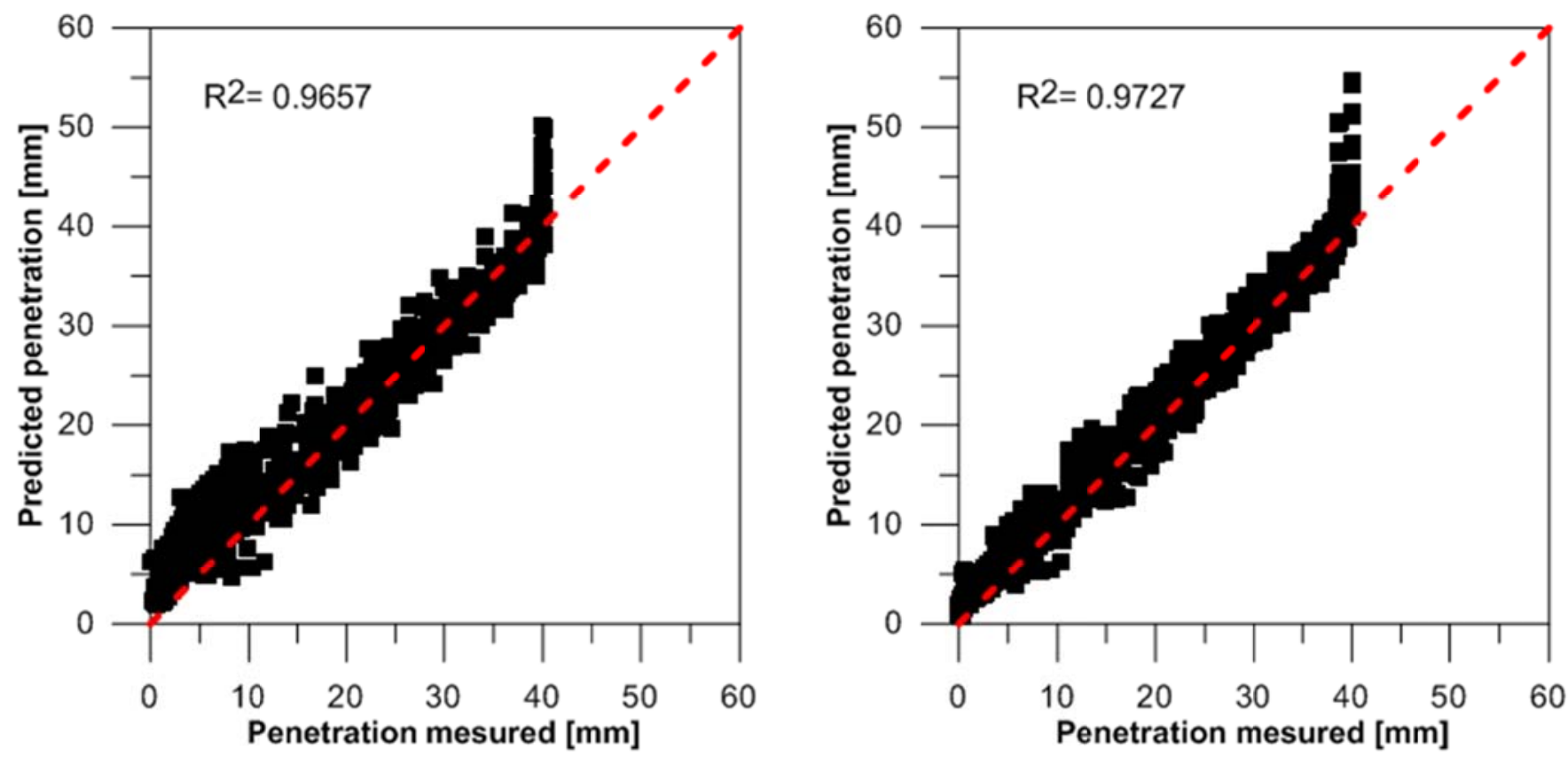

Fig 13 